\title{
LA POLITOLOGÍA MEXICANA. UNA VISIÓN DE CONJUNTO EN TIEMPOS INCIERTOS
}

MEXICAN POLITICAL SCIENCE. A GENERAL OVERVIEW IN UNCERTAIN TIMES

Víctor Alarcón Olguín*

\section{RESUMEN}

Se realiza un acercamiento al estudio y desarrollo de la ciencia política mexicana, poniendo énfasis en sus dilemas organizativos y sus procesos de institucionalización tanto en los ámbitos nacional y regional. Si bien cabe constatar que ambos procesos han experimentado un desarrollo alentador en las últimas cinco décadas, persisten dinámicas de desigualdad sustantivas en diversos ámbitos que obligan a reflexionar sobre las acciones que puedan promoverse para corregir dichas asimetrías.

Palabras clave: Ciencia política, dinámicas de organización institucional, tendencias y prácticas de docencia e investigación, México.

\section{ABSTRACT}

A national and regional approach is made up to the study and development of Mexican political science, by emphasizing its organizational and institutional dilemmas. Although it should be noted that both processes have experienced an encouraging development in the last five decades, substantive inequality dynamics persist in various areas that force us to reflect on the actions that can be promoted to correct such asymmetries.

Keywords: Political science, dynamics of institutional organization, trends and practices in teaching and research, México.

Recibido o9 de junio de 2021 y aceptado 28 de junio de 2021

* Profesor-Investigador Titular «C» en el Departamento de Sociología, UAM-Iztapalapa, Área de Procesos Políticos. Miembro del sni, nivel iı. <alar@xanum.uam.mx>. 


\title{
ESTACIÓN DE PARTIDA HISTÓRICO-CONTEXTUAL. DE "MESAS SEPARADAS", "MR. PERESTROIKA", EL "MANIFIESTO DE POPAYÁN»Y LA «RED DE POLITÓLOGAS»
}

\begin{abstract}
Los viejos y rígidos debates y limites -ciencia frente a religión, ciencia frente al arte, ciencia frente a la ética tradicional-ya no bastan. Deberíamos impacientarnos con ellos. Necesitamos una perspectiva más amplia, más generosa, más imaginativa. Por encima de todo, quizá necesitamos 3 cosas que una cultura cientifica nos puede aportar: el sentido del prodigio individual, el poder de la esperanza y la creencia nitida-pero rastreadora-de un futuro para el planeta
\end{abstract}

Richard Holmes La edad de los prodigios (20I2: 608)

A la memoria de Gustavo Ernesto Emmerich Isaac, Adrián Gimate-Welsh Hérnández, Arturo Ibarra Ojeda, Jorge Fuentes Morúa y Luis Rodríguez Ojeda, dignos formadores de politólog@s de la UAM-I

Ll presente ejercicio se sustenta metodológicamente desde la perspectiva
de la investigación-diagnóstico y apunta a generar algunas líneas interpretativas respecto a la evolución institucional y organizativa de la ciencia política mexicana a partir de un examen de diversas bases de datos, identificando casos y comparando variables que se pudieron ponderar tanto en los ámbitos nacional como subnacional. Igualmente, se ofrece una ruta de análisis que intenta acercarse a mecanismos confiables de tipo diacrónico amparados tanto en sus elementos de comparación, contextualización histórica y aplicabilidad de los conocimientos adquiridos, a partir de la formulación de algunas recomendaciones en materia de fortalecer las políticas e instancias de organización e institucionalización de la disciplina. 
Sin embargo, cabe señalar que varias de las afirmaciones que se enunciarán a lo largo de la presente exposición pueden ser calificadas como subjetivas, especulativas e incluso cuestionables, en tanto los datos recopilados que sirven como apoyo central para situar y valorar el estado actual de la politología mexicana se valoran sin excluir la propia experiencia de vida y práctica profesional que se ha vivido en el campo disciplinario, mismo que indudablemente ha tenido una dinámica de crecimiento en las últimas cuatro décadas, aunque se siguen manteniendo importantes brechas de desigualdad respecto a tópicos centrales como su concentración regional, la existencia de desequilibrios importantes en las agendas de investigación y docencia que se practican, así como una ausencia de equidad entre géneros. ${ }^{2}$

Lo aquí señalado lleva entonces a preguntarse de qué manera la ciencia política mexicana se encuentra ante el desafío de experimentar una suerte de proceso de apertura similar al que animó a principios del presente siglo, al fenómeno de la rebelión conceptual y organizacional encabezada desde uno de los epicentros mundiales de la politología, como lo son los Estados Unidos, a partir del movimiento de "Mr. Perestroika», cuyo famoso correo electrónico dirigido a la redacción de la connotada revista American Political Science Review (APSR) y la directiva de la Asociación Estadounidense de Ciencia Política (APSA), con fecha del 17 de octubre de 2000, denunciaba el estatus de monopolio e irrelevancia metodológica en que había caído la disciplina, debido al predominio excesivo de los enfoques cuantitativos en los contenidos y orientación de las publicaciones auspiciadas por dicha organización, en detrimento de otras expresiones, como los análisis de tipo histórico, cultural o filosófico-político (Mr. Perestroika, 2000; Monroe, 2005). ${ }^{3}$

${ }^{2}$ Este ejercicio pretende dar continuidad a aproximaciones que se han realizado en textos previos (Alarcón Olguín, 20II, 20I2, 20I6, 20I7), en los cuales se han revisado estos temas con objeto de generar una agenda de investigación disciplinaria como lo implica valorar la institucionalización y el contexto histórico de los procesos de docencia, investigación y reconocimiento que caracterizan a la comunidad politológica en el marco de la política científica imperante en el país respecto a las ciencias sociales.

${ }^{3}$ Desde luego, no puede omitirse que previo a la emergencia de dicho movimiento, desde tiempo atrás la discusión respecto a las condiciones de práctica y rumbo a seguir por la ciencia política han mantenido un notable impulso con libros o trabajos como las posturas de David Easton (1985) o Luigi Graziano (1987) hablando de los complejos retos 
En consecuencia, este intento de "corte de caja» disciplinario pretende moverse y condensar inicialmente en esta sección -en una suerte de «estado de arte»- las aportaciones hechas por valiosos trabajos que se han dirigido a ofrecer balances interpretativos generales de la disciplina politológica, y generados para explorar los ámbitos internacional, latinoamericano, nacional y subnacional, a partir del empleo de diversas metodologías y técnicas. Entre estas, se pueden resaltar, por ejemplo:

a) El examen bibliométrico de revistas y libros, con el propósito de ubicar las tendencias del «mainstream» dominante mediante el uso de los esquemas de citación, lo cual permite ver el alcance y difusión de las redes de influencia generadas por autores y temáticas dentro del

\begin{abstract}
y agendas en que se había diversificado la ciencia política después de la Segunda Guerra Mundial, en el contexto de la Guerra Fría y la crisis del Welfare State, tanto en Estados Unidos como en Europa, lo cual se reflejaba en tres importantes dilemas: desarrollar una reconstrucción del lenguaje, redefinir la identidad disciplinaria y revalorar la importancia del (los) método(s) en la formación de conocimiento relevante y aplicable para la resolución de los problemas. También resultó significativa la postura de David M. Ricci (1984), hablando de la «tragedia de la Ciencia Política», expresión retomada años más tarde por Danilo Zolo en 2007, la cual se ubicaba en los problemas de la profundización de la brecha entre los sectores cuantitativo y cualitativo del gremio. Le siguió la poderosa tesis de la clasificación y balance de la disciplina hecha por Gabriel Almond en I990 a partir de las llamadas "mesas separadas», con las cuales se mostraba una división puntual entre sus orientaciones ideológica de izquierda y derecha, combinados a su vez con los énfasis de consistencia dura o blanda en lo relativo al uso de los métodos de tipo cuantitativo o cualitativo para el tratamiento y encuadre de las problemáticas de estudio. Y ya en el presente siglo, la discusión se reavivó con las provocadoras reflexiones hechas por Giovanni Sartori (2004), preguntándose -y preocupándose- abiertamente respecto a cuál era el futuro de la disciplina, cuestión leída en muchas latitudes de manera muy rápida como una suerte de obituario. O también la postura de Phillippe C. Schmitter (2003) vinculada al dilema de ver a una disciplina atrapada en sus exigencias empiricistas para responder efectivamente a las necesidades de acción y entendimiento del mundo actual que ha surgido en el marco de la globalización. Mas adelante, en el siguiente apartado, se retomarán algunos de los impactos concretos que estos debates generaron a su vez en los ámbitos de la ciencia política latinoamericana y mexicana, partiendo de las discusiones asociadas con la historia, la identidad, los espacios institucionales, los contextos y las prácticas que caracterizan a las y los profesionales del gremio.
\end{abstract}


medio, con el ánimo de señalar la persistencia de un parroquialismo nacionalista, además de advertir la baja internacionalización regional y global de las y los practicantes de la disciplina (Rivera y Salazar Elena, 20II; Puente Martínez y Martínez Valdés, 20I7; Codato, Madeira y Bittecourt, 2020).

b) Los acercamientos construidos para situar la coyuntura histórica y los contextos de influencia que definen a una «toma de posición militante» respecto a los propios procesos de gestación y desarrollo institucional de la disciplina para que la misma responda y evolucione conforme a las necesidades políticas de los regímenes de gobierno que han imperado en los países de acogida, destacándose así la importancia o no de la centralidad del Estado en dicho proceso a partir de sus necesidades, además de constatarse las limitaciones impuestas por los contextos de democracia o dictadura que han alentado o inhibido la presencia y desarrollo de la disciplina en dichos contextos nacionales (Ravecca, 2019; Contreras Montellano y Puga Espinosa, 2019).

Pero también en esta línea analítica se puede rescatar la idea de discutir los procesos de introspección narrativa, asociados con la presencia de la memoria y la reconstrucción vocacional que permiten trazar una suerte de "process tracing" retrospectivo respecto a la formación de los valores e ideas con las cuales se aprovisionan quienes practican la disciplina politológica, con el ánimo de entender y entenderse a sí mismos/as, siguiendo así procesos de autoexploración y autoubicación respecto a las condiciones del oficio y desempeño profesional (García Díaz, 20i6; Lave, 200I).

c) Los estudios dirigidos para evaluar la calidad y contenidos curriculares e institucionales que definen a los programas de docencia e investigación de la disciplina existentes en las universidades nacionales que hoy ofrecen la enseńanza de la disciplina, lo cual implica también revisar las llamadas redes de influencia y difusión del conocimiento, donde los niveles del "prestigio» y el «reconocimiento» se reflejan como los indicadores principales para medir la fortaleza y duración de los grupos de poder (y los líderes académicos que los encabezan) dentro de las estructuras y redes científicas que se han forjado al paso del tiempo, lo que permite trazar con precisión los espacios, 
redes y evidencias de (re)producción existentes dentro de dichas instituciones educativas públicas y privadas, viniendo a conformar así un «establishment», «régimen» o "status quo» predominante dentro de la disciplina tanto en sus ámbitos local, nacional e internacional (Duque Daza, 2020; Vallés, 2020; Altman, 2017).

De esta manera, uno se podría cuestionar acerca de las condiciones de competencia y habilidades con que se pretende dar contenido a los planes y programas de estudio en materia docente, tanto para la formación de profesionales no académicos, así como de quienes pretenden mantenerse dentro de la enseñanza y la investigación. También se puede percibir una crisis creciente, sobre todo en materia de comparar las condiciones de ingreso y permanencia individual dentro de la carrera académico-profesional, como consecuencia de las directrices de la política científica y la cultura de la investigación que son pactadas y desarrolladas desde de los Estados nacionales, pero que han carecido históricamente de los apoyos presupuestales suficientes que permitan impulsar como prioridad los mecanismos e instrumentos de organización colectiva que puedan aprovechar dicha inversión pública y privada, para así generar los beneficios e impacto social de mediano y largo plazo que podrían obtenerse con la aplicación de dichas acciones, en concordancia precisamente con los objetivos de las políticas científicas y el proyecto estatal-nacional en curso (Remedi Allione y Ramírez García, 20ı6; Pérez Mora, Prieto Quezada y Castellanos Gutiérrez, 20I2).

d) También pueden mencionarse los trabajos interesados en incursionar y conocer los procesos de formación e institucionalización histórica de la disciplina politológica a lo largo y ancho del continente americano, así como sus equivalentes aplicados en lo relativo al proceso experimentado en el ámbito mexicano, acciones que se han venido consolidando de manera puntual gracias a la agenda de trabajo común condensada en el Manifiesto de Popayán, suscrito inicialmente en el año 2014 en el marco del III Congreso Nacional de Asociación Colombiana de Ciencia Politica, y el cual tomó a su vez inspiración del surgimiento en el año de 2012 del Grupo de Investigación sobre la Historia de la Ciencia Política en América Latina (GiHcipolal), 
de la Asociación Latinoamericana en Ciencia Política (ALACIP) en Quito, Ecuador. Bajo este paraguas analítico, también se impulsan importantes elementos de estudio como la comparación de los estilos de trabajo, la presencia de organizaciones y asociaciones nacionales o temáticas, un fenómeno que ha podido despegar sobre todo a partir de la formación en el año 2002 de la referida ALACIP, lo que ha permitido sistematizar y coordinar el trabajo de sus homólogas nacionales con la realización de congresos y publicaciones de alcance continental (Ángel Baquero, 2020; Flores Mariscal 2016; Bulcourf, Gutiérrez Márquez y Cardozo, 20I5; Arellano Ríos, 20I5; Barrientos del Monte, 20I4; Duque Daza, 20I4; Vidal de la Rosa, 20I3).

Y, por otra parte, este tipo de trabajos han permitido estudiar las maneras con que se han ido tomando decisiones relativas a la definición de los planes, programas de estudio y de los mecanismos de los sistemas de ingreso, promoción y permanencia dentro del medio laboral, con la idea de definir si se han generado condiciones propias en nuestros medios para permitir la generación de conocimiento, o simplemente seguimos adaptando experiencias de evaluación y cultura organizacionales derivadas de los contextos presenciados en los países más avanzados (Puelló-Socarrás y Jiménez, 20I9; Tanaka y Dargent, 20I5; Yocelevzky, 20I4; Munck, 2007).

e) Igualmente, ha sido importante el desarrollo de las acciones para dar visibilidad -y combatir- la desigualdad en la participación de las mujeres en el medio de la ciencia política, sobre todo gracias a la fundación durante la pasada década del movimiento \#NoSinMujeres y de la Red de Politólogas en el año 20ı6, cuyo impacto en los espacios nacionales de la región latinoamericana ha sido muy significativo para comenzar a discutir e incluir la perspectiva de género como un elemento central en la investigación y la enseńanza de la disciplina. En este sentido, la combinación de las líneas de acción previamente mencionadas y que se sistematizan en un programa de trabajo puntual (Manifiesto de la Red de Politólogas, 2019) presenta un acento particular en lo relativo a identificar las brechas existentes y cuáles pueden ser las acciones afirmativas pertinentes para disminuirlas, con el consiguiente factor de impacto en términos de lograr una verdadera 
igualdad y reconocimiento sustantivos dentro del gremio, y desde luego en los espacios de acción e influencia públicas (Freidenberg y Suárez Cao, 202I; Roqueñí Ibargüengoitia, 2OI4).

Ahora bien, todas estas rutas de investigación aquí esbozadas nos obligan a visualizar un esfuerzo de análisis ubicado más allá del simple bienestar personal que se pueda poseer -de manera legítima, por cierto- por parte de una colectividad académica hoy presionada bajo el mecanismo esencial de "publicar o perecer», debido precisamente a las reglas y características que han prevalecido desde el último cuarto de siglo xx hasta lo que llevamos de la presente centuria, respecto a las maneras en que se han redefinido los estilos de producción científica y en el marco de la llamada sociedad del conocimiento, cuyos elementos están a su vez influidos por el papel con que la cultura académica se desarrolla en las instancias tradicionales, como son las universidades y centros de pensamiento (incluyendo aquí los famosos think-tanks patrocinados desde las corporaciones privadas o las ONG generadas desde segmentos específicos de la sociedad civil) (Salas-Porras, 20I8).

De esta manera, se han venido prefigurando espacios de discusión muy relevantes respecto a considerar si la ciencia política no solo evoluciona en relación con su objeto y método, sino que su naturaleza y sentido también implican analizarla en términos de los contextos o coyunturas motivacionales que le han venido dando una dirección y una densidad identitaria en el sentido clásico de la socio-génesis, las teorías de campo configuracional o de la autorreflexión, mismas que permitan denominar y organizar sus capacidades descriptivas, explicativas y predictivas, a efecto de que su incidencia sea verdaderamente sustancial en el espacio de la política real (Retamozo, 2009).

Para el caso de América Latina, como bien lo sabemos, la presencia de este tipo de organizaciones y dinámicas no siempre ha gozado (como vuelve a ocurrir en los tiempos actuales) de las mejores condiciones para que puedan ser considerados como puntos de referencia e influencia obligados entre quienes ejercen el poder en medio de una de las etapas más complejas que la humanidad ha debido afrontar en el tiempo reciente. De esta manera, no puede omitirse que las políticas educativas y científico-tecnológicas en general están atravesando por una baja sensible en sus condiciones institucionales de apoyo para el cumplimiento de sus objetivos (Acosta Silva, 2020). 
Las ciencias sociales en general -y la ciencia política en particular-, por desgracia no han podido sustraerse a estas circunstancias por las que atraviesan tanto los gobiernos neoliberales como neopopulistas, lo que parece entonces no hacer mayor diferencia. Adicionalmente, el mencionado declive de las universidades y el quehacer educativo se ha visto agravado por una fuerte crítica respecto a su falta de capacidad para ofrecer respuestas viables a problemas precisos (como acontece hoy día con motivo de la pandemia global del virus Covid-r9), lo cual se viene argumentando hasta al punto de exaltar que ello forma parte de una suerte de «tiranía del mérito» a partir de la cual las ciencias sociales en la actualidad están claramente ensimismadas y desconectadas del propio curso de los acontecimientos, lo que debería obligar(nos) a promover una clara recomposición de los esquemas de premiación y reconocimiento al desempeńo, tratando de reencauzarlos por la vía de la utilidad social y el bien común (Sandel, 2020).

Por ello, en nuestro siguiente apartado vamos a generar algunas líneas de discusión epistemológica respecto a la manera particular desde la cual estos debates han prevalecido en el ánimo de orientar al curso de la ciencia política mexicana y que, a la vez, nos servirán como preámbulo al ejercicio de aproximación evaluativa que se ha aplicado a efecto de ubicar el estado actual de la disciplina mediante un acercamiento a la condición que guardan sus principales indicadores de desempeño institucional y colectivo, como lo será la revisión panorámica de la participación de la comunidad politológica en el Sistema Nacional de Investigadores (SNI) del Conacyt.

\section{ESTACIÓN EPISTEMOLÓGICA. ¿EXISTE LA POLITOLOGÍA MEXICANA EN TANTO UN VERDADERO ESPACIO-RED DE CONOCIMIENTOS?}

Como una suerte de dilema originario, la ciencia política mexicana no está exenta de repetir el dilema de origen que aqueja a la disciplina mundial en su conjunto respecto a discutir acerca de su objeto y de cómo ponderar su contribución social e histórica, y cómo ello, a su vez, la ha mantenido atrapada alrededor de ponderar si su esencia y sentido se sustentan a partir de sus elementos cualitativos o cuantitativos, en tanto mecanismo de construcción, 
explicación, implementación y validación de los conocimientos que produce (Schmitter y Blecher, 202I; Garcé, 2020).

En estas circunstancias, la reflexión sobre el objeto y sujetos que guían su quehacer siguen captando el interés de las y los principales exponentes de la disciplina, acaso justamente con el propósito de responder así a las necesidades del momento histórico, a la par de posicionarse respecto a las propias tradiciones y aportaciones que los estudios politológicos han podido ofrecer para entender la naturaleza del quehacer de los actos de poder y sus consiguientes impactos para nuestra sociedad. La pregunta en torno a la naturaleza estrictamente académica o de incidencia e impactos concretos con que se debe guiar su enseñanza, así como la conformación de sus habilidades y competencias, es un tema sobre el cual se podría dar cuenta en forma específica cuando se revisa de manera panorámica cómo son vistos sus impactos por sus propios practicantes. Este largo debate contextual entre academicismo e incidencia pública concreta como bases de la misión politológica actual nunca ha estado ausente como telón de fondo respecto a las principales líneas de reflexión y estudio, tanto en México como a nivel mundial (Zamitiz, 2020, Duque Daza, 2020; Murillo, 2015; Cuéllar y Caicedo, 2015).

La ciencia política históricamente ha tenido dos importantes rutas de ubicación configurativa en el campo de las ciencias, consistente en ver sus influencias de orden interno y externo, como lo han resaltado epistemólogos clásicos como Mario Bunge, al preguntarse si las ciencias sociales deben sostenerse o no bajo la premisa de un "programa fuerte» autónomo que le ofrezcan sentido y direccionalidad a sus objetivos y modelos de acción, lo que igualmente le han permitido pensarse a sí mismas en términos de sus normas, conductas y estructuras, así como pretender (auto)definir(se) desde sus conceptos, clasificaciones y aplicaciones (Bunge, 1998), o bien moverse dentro de la ruta del relativismo y las condiciones crecientes que llaman a la hibridación entre las disciplinas, cuestión que ha prevalecido con la idea de denominar un espacio en plural de las «ciencias políticas» (que le mantiene entonces en una suerte de "galaxia local» junto con otros campos de conocimiento como la administración pública, las relaciones internacionales, e incluso con las ciencias de la comunicación), como se le promovió desde la experiencia continental europea, a diferencia del universo anglosajón que 
ha defendido la nítida separación e independencia de la ciencia política en singular frente a la demás de áreas de conocimiento (Panebianco, 20II; Sartori; 20II; Nohlen, 20II; Pasquino, 20I0; Alcántara, I993; Blondel, I978).

En una lectura más amplia, se pueden valorar también las posturas de corte pluralista que no solo ven la ciencia política inmersa en su interacción usual con el derecho, la sociología, la filosofía o la historia, sino que ahora cabe situarla desde su interacción con las teorías de la elección racional, la prospectiva, la psicología cognitiva, los estudios comparados y más recientemente con el desarrollo de la minería de datos y el uso obligado de procesadores estadísticos, con la idea de manejar elementos de comparación más amplios, así como construir modelos sostenidos a partir del uso de inferencias y probabilidades como medio de la comprobación de relaciones causales o de asociación. Esto es, implica ver la ciencia política incluso interactuando y dialogando abiertamente con áreas como las ingenierías, la biología o la psicología, en términos de explorar las bases más profundas del comportamiento humano bajo el impulso de la modelación de las emociones o la orientación de las decisiones bajo las rutas del control y los factores de oportunidad o riesgo (Aldeguer Cerdá, 2015; Della Porta y Keating, 2013; King, Lehman y Nie, 2009).

Las formas particulares de apropiación y difusión del conocimiento científico se integran en un ámbito de redes cada vez más complejo, intentando pasar de estructuras estrictamente ideográficas hacia las de tipo nomotético, como lo pensaban las primeras generaciones de pensadores sistémicos, positivistas y conductistas, en detrimento de las posturas de corte culturalista o marxista, cuya base de análisis usualmente se ha movido más bajo la idea de visualizar los procesos históricos bajo condiciones de apropiación y conflicto. O, incluso, fueron vistos (y lo siguen siendo) bajo la premisa de señalar el sentido y utilidad «revolucionaria» o «reaccionaria» del uso de las estadísticas, de las técnicas de planificación o de la demoscopia (Bourdieu, 2003; Shaw, 1978; Salomón, 1974; González Casanova, 1968). La búsqueda del conocimiento se mueve, así, de la simple creencia hacia la exigencia de lograr certezas y verdades que permitan predecir y resolver problemas concretos de manera regular y no solo de manera coyuntural o contingente, aunque ello también implique cuestionarse puntualmente sobre las formas 
de transmitir y enseñar el conocimiento de la política y lo político bajo una perspectiva de responsabilidad y criterios éticos (Miller, 1977).

De esta manera, nos hemos ido desplazando hacia el predominio actual de que debe dársele una mayor prioridad al tema de la técnica y los datos que acompańan al ejercicio de la investigación, aunque estos, a su vez, vayan menos respaldados de un ejercicio previo capaz de situar adecuadamente las preguntas que los originan, de reflexionar acerca sus alcances normativos e incluso las implicaciones de tipo moral que pudieran estar presentes, mismas que ahora son usualmente vistas como «externalidades» o factores subjetivos poco relevantes frente a la contundencia de los niveles de significancia que llenan ahora muchas de las páginas de artículos y libros dentro de la disciplina.

Figura I. Retos metodológicos de la ciencia política desde la perspectiva interdisciplinaria.

- Política Comparada

- Estudios de Área (Especialmente América Latina)

- Regímenes Políticos
- Políticas Públicas Sectoriales

- Procesos Judiciales y Legislativos

- Análisis y evaluación Institucional / Organizacional de la AP

- Estudios comparados con alcance subnacional / municipal

\section{(1) \\ ADMINISTRACIÓN PÚBLICA DERECHO INTERNACIONALES \\ (DERECHO

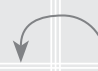 \\ humanidades \\ Filosofía \\ ECONOMÍA \\ Historia \\ PSICOLOGÍA \\ Antropología \\ SOCIOLOGÍA \\ Comunicación}

Estudios de

Género

- Modelos formales

- Metodos cuantitativos

- Path dependence

- Process tracing

- Prospectiva

- Modelos ideográficos

- Métodos cualitativos

- Teorías e ideologías

- Análisis de Discurso / Marcos

- Memoria / Narrativa

Fuente: Elaboración propia, con base en los criterios de King, Lehman y Nie (2009). 
E igualmente podemos plantearnos este mismo problema en el sentido opuesto, cuando solo se trata de imponer posiciones de principio, sin mayor respaldo que la simple intuición personal. Por desgracia, basar los alcances y el progreso de una disciplina sobre estos argumentos la vuelve todo menos que una ciencia, sino que se queda en el terreno del dogma o la ideología militante, por muy justas y concretas que sean sus demandas de origen. Se trata, entonces, de sujetos o actores políticos poco tolerantes, plurales e incapaces de dialogar, dado que lo «evidente» o lo «obvio» no son entonces motivo de reflexión alguna (Echeverría, 2009).

$\mathrm{El}$ «programa fuerte» de la ciencia sustentado en el peso central del método y las técnicas que van surgiendo y perfeccionándose en un ejercicio de autoevaluación y mejora continua se ha desvirtuado con el paso del tiempo para convertirse en una suerte de concurso solo interesado en mostrar mecanismos más sofisticados para medir y comparar alguna capacidad o fenómeno específico. Esta dinámica no podría criticarse en sí misma, porque sin duda estamos necesitados de que la disciplina crezca y se aliente la adopción y aceptación de conocimientos surgidos desde análisis robustos. Sin embargo, el proceso se ve carente de «alma y espíritu de cuerpo» desde las realidades nacionales, lo cual obliga a pensar acerca de cómo se le puede seguir dando forma y contenido ético a nuestra comunidad profesional, lo cual evidentemente se ve influido por los problemas propios del interés con que los Estados nacionales han facilitado su desarrollo, a partir de la creación de los sistemas e instituciones de promoción para la docencia e investigación, si bien ello genera los clásicos problemas en materia de asimetrías, brechas e (inter)dependencias existentes no solo entre las naciones más avanzadas y las de tipo periférico, sino que ello se extiende entre la capital y las provincias en cada uno de los países donde se fueron instaurando y aplicando dichas políticas de generación y promoción científica.

Como aconteció en México y otros actores destacados de la región latinoamericana, lo aquí indicado ha provocado una situación que sigue preocupando en la medida en que se realizan preguntas en torno a los problemas de cómo ubicar, distinguir y alentar estilos regionales pertinentes en el quehacer científico, sin omitir los llamados a impulsar acciones dirigidas a reconocer la presencia de problemas asociados con la carencia de oportunidades, derivados de la marginación o la discriminación por motivos de género, etnia o 
ideología, y que han venido a incrementar las manifestaciones del atraso y la dependencia estructural de nuestros modelos de reflexión teórica e incidencia pública en materia de la actividad social (Contreras Montellano y Puga Espinosa, 2017; Béjar Navarro y Hernández Bringas, 1996; Herrera, 1975).

Sin duda, todas estas visiones interpretativas aportan -lo seguirán haciendo- para que haya opciones sólidas que permitan evaluar el alcance e impacto de la ciencia política en los contextos global, nacional y regional, en los cuales se ha movido de manera por demás vertiginosa. De ahí que resulta pertinente responder a las siguientes interrogantes:

a) ¿Puede hablarse, entonces, de la ciencia política mexicana como una comunidad científica organizada y que responda a la existencia consolidada de programas y objetivos comunes en sentido estricto?

b) ¿Cuáles son los retos y el tipo de respuestas que se pueden esperar de la ciencia política mexicana ante las condiciones limitadas con que se está enfrentando nuestro entorno?

La mayoría de las y los expertos que han revisado a lo largo de cinco décadas el devenir de la politología mexicana, tanto en los contextos internacional como regional, han puesto el acento sobre las condiciones con que la disciplina ha venido generando una reflexión sobre sí misma, cuál debe ser su rumbo, si esta se halla en condiciones efectivas de considerarse como capaz de guiar su desarrollo y contribuciones bajo una base metodológico-técnica enteramente "científica» y sustentada sobre los principios de contrastación, predicción y réplica verificable. Las respuestas siguen siendo ambivalentes por cuanto no hay acuerdo respecto a si se han alcanzado las condiciones mencionadas, aunque hay un predominio respecto a indicar un saldo negativo de este proceso. Se sigue cuestionando si la disciplina posee siquiera un vocabulario esencial o una capacidad de lectura pertinente con el cual pueda denotarse a los sujetos y los objetos de estudio, así como valorar si se ha logrado o no un verdadero espacio de influencia y desarrollo en el espacio de las ciencias sociales en México (Bravo Ahuja, 20ı6: Muñoz Patraca, 2009; Loaeza, 2005; Rodríguez Araujo, 200I; Bokser-Liwerant, 1999; Torres Mejía, I990; Hoyo Arana, I980; Meyer y Camacho, I979; Meyer, 197I). 
Es por ello que en la tercera sección de este trabajo se pretenderá entrar de lleno a una exploración puntual de la disciplina mediante la ponderación y ubicación comparada de algunos indicadores que nos permitan situar el nivel de las problemáticas que se han enunciado hasta ahora de manera panorámica, y con ello tratar de ofrecer algunas ideas a manera de recomendaciones concretas para tratar de afrontarlas.

\section{ESTACIÓN ANALÍTICA. UN RETRATO DE FAMILIA DE LA POLITOLOGÍA MEXICANA}

Por fortuna, los años recientes han venido ofreciendo mecanismos cada vez más minuciosos en lo relativo a promover procesos de (auto)evaluación de los espacios institucionales en materia de docencia e investigación, tanto en los ámbitos de casos específicos como en el plano de una revisión comparada de un campo disciplinar en sus niveles micro, meso y macro, además de generar descripciones muy buenas tanto en sus dimensiones e implicaciones cuantitativas como cualitativas (Kent Serna, Álvarez Mendiola, González Rubí, De Vries y Ramírez García, 2003).

Los estudios provenientes desde la historia y la sociología de las profesiones (igualmente conocida como prosografía) son una excelente línea metodológica que permiten conocer, entre varias cosas, las condiciones generales con las cuales se desenvuelve un espacio o hábitat académico, mediante la observación de su estatus y reglas legales; conocer los mecanismos organizacionales que alientan su desarrollo, estancamiento u cambio; revisar las dinámicas y prácticas culturales desde las que se construyen elementos como el prestigio, la socialización y comunicación entre sus integrantes, así como realizar la comparación de su desempeños respecto a otras realidades nacionales (Elliott, I975).

Las aproximaciones de conjunto para examinar el caso específico de las ciencias sociales mexicanas comenzaron a fluir de manera muy amplia gracias a la gestación y promoción de dichos campos de conocimiento de manera posterior a la Segunda Guerra Mundial y con la entrada del país al discurso de la modernidad y el ascenso de profesionistas civiles a las esferas burocráticas, lo cual hizo indispensable la necesidad de alentar la formación 
específica de expertos que pudieran cubrir ámbitos de tareas gubernamentales allí donde la visión de los juristas, los economistas o los ingenieros ya no eran suficientes (Rodríguez Sala-Gómezgil y Chavero González, I982).

La emergencia a partir de I95I de la Escuela Nacional de Ciencias Políticas y Sociales en la Unam marca un hito concreto que permite ubicar con precisión el nacimiento de este importante sector en el campo académico. Y de manera específica se dio acta de nacimiento a una disciplina concreta como la ciencia política, si bien, como se mencionó, la concepción del campo académico le vinculó en plural (como incluso lo hace hasta la fecha) con campos adyacentes como la administración pública, las relaciones internacionales, la comunicación y la sociología.

De igual manera, el lento devenir de la ciencia política mexicana se vería asociado con decisiones de política científica, como la formación de los primeros programas en dicha materia en los espacios privados y estatal-subnacionales con la creación en 1964 de los programas de Ciencias Políticas y Administración Pública en la Universidad Iberoamericana y la Universidad Autónoma de Baja California en 1964, respectivamente, y que al momento actual nos lleva a un registro de cerca de un centenar de instituciones que la imparten a la largo del país (Anuies, 2020)

$\mathrm{Y}$ adicionalmente nos tenemos que remitir a decisiones de política científica, como la formación del primer posgrado nacional en la materia desde la Unam (maestría y doctorado entre los años 1968 y 1969), la creación del Conacyt en 1970, de cuya acción se derivó también la posibilidad de articular programas más integrales, como el envío masivo al exterior de jóvenes con la idea de que obtuvieran posgrados en universidades de prestigio y con ello alimentar con personal calificado a la cantidad importante de universidades públicas y estatales que se venían creando en esos años.

Además, fue el tiempo que permitió por vez primera la presencia de procesos de formación de organizaciones con una visión gremial y profesionalizante, como lo fue el caso del Colegio Nacional de Ciencias Políticas y Administración Pública en 1974 (disuelto en sentido práctico hacia el año 2006), al tiempo que en 1977 se daría la integración del Consejo Mexicano de Ciencias Sociales (comecso), y con ello se pudo dar un proceso de organización y sistematización de redes de conocimiento, las cuales se apoyaban con la acción de la Asociación Nacional de Universidades e Instituciones 
de Educación Superior (Anuies), creada a su vez desde el año I940, y a la que luego se sumaría la Federación de Instituciones Mexicanas Particulares de Educación Superior (FIMPes). Pero, sin duda, un gran punto de aliento lo sintetizaría la formación en 1984 del Sistema Nacional de Investigadores, además de que se darían los pasos para ir creando asociaciones de profesionales que comienzan a cultivar campos de subespecialidad específica, como lo sería a partir de 1989 el Grupo Especializado en Estudios Electorales de la comecso, del cual derivaría en 1998 la Sociedad Mexicana de Estudios Electorales (someE), como en el año 20or se daría paso a la Asociación Mexicana de Estudios Parlamentarios (AMEP).

El crecimiento constante de estos procesos nos muestra la necesidad de cohesionar y dar forma al espacio de las ciencias sociales mexicanas, lo que vendría a consolidarse con la presencia de organizaciones consultivas con incidencia en la determinación de las políticas científicas del Estado mexicano, como la Academia Mexicana de Ciencias (AMC, fundada en 1959), el Foro Consultivo Cientifico y Tecnológico (FCCyт, formado en 2002) y más recientemente la Red ProCienciaMx, creada en 2019.

Por el lado de apoyar el desarrollo de esquemas paralelos a los sistemas de reconocimiento y estímulos para el desempeño académico, se sumaron acciones desde la Secretaría de Educación Pública como el Programa de Mejoramiento del Profesorado (Promep, hoy Prodep), la labor en materia de acreditación de la calidad docente de licenciatura por parte de los Comités Interinstitucionales de Evaluación de la Educación Superior (CIEEs) y el Consejo para la Planeación de la Educación Superior (COPAes), al cual pertenece la Asociación para la Acreditación en Ciencias Sociales (ACCECISO), así como del Programa Nacional de Posgrados de Calidad (PNPC) para evaluar el nivel docente de posgrado a cargo del Conacyt, así como se generó la creación de un modelo similar en el ámbito de la indexación de las revistas científicas mexicanas (Bensusán y Valenti, 20I8).

Bajo este contexto, de manera más reciente, la dinámica gremial de la comunidad politológica se reanudó con la formación en el año de 20I2, tanto del Consejo Mexicano de Ciencia Política (comicip), como de la Asociación Mexicana de Ciencias Políticas (AMECIP), instancia que goza hoy del reconocimiento respectivo tanto la ALACIP a nivel regional, como de la 
International Political Science Association (IPSA) en el contexto mundial (Alarcón Olguín, 20I7; Barrientos del Monte, 20I5).

Figura 2. Sistema Científico Nacional y las Ciencias Politicas. Una visión de conjunto.

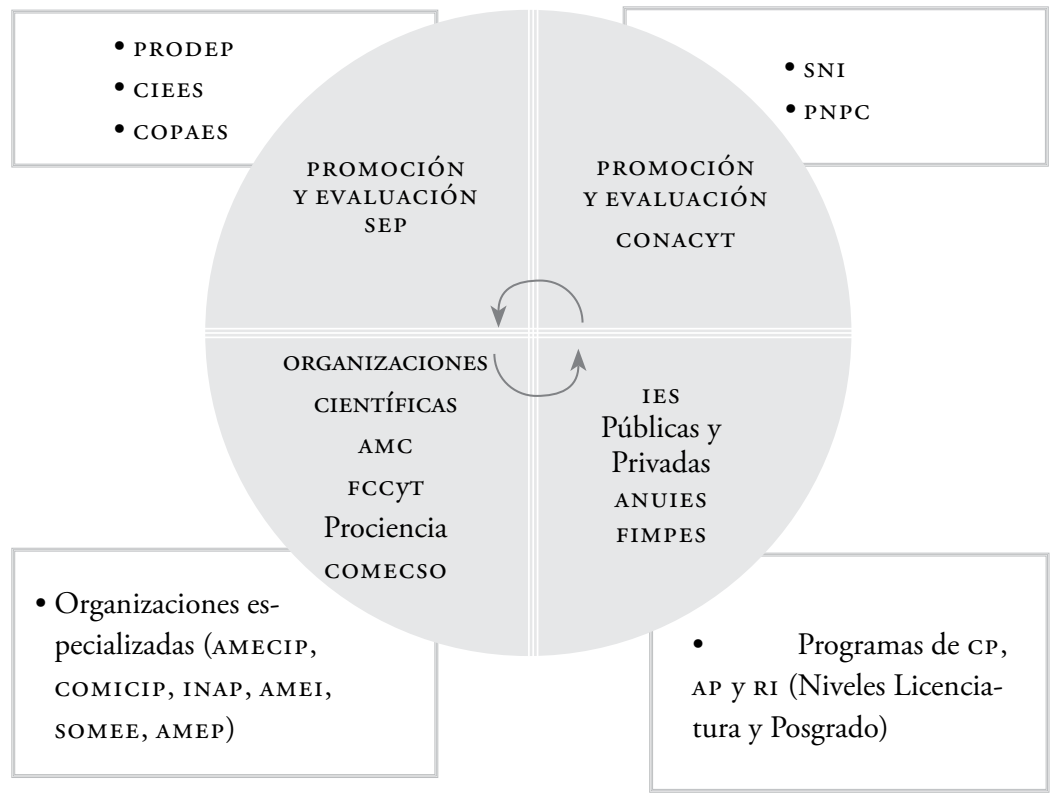

Fuente: Elaboración propia.

Como puede advertirse, el trazo del espacio académico en el cual se mueve una disciplina específica (en este caso, la politología mexicana) nos obliga entonces a revisar su desempeño bajo la idea de identificar cuáles son las acciones de política científica que deben ponerse sobre la balanza. De manera específica, la existencia de datos ad hoc sobre la trayectoria de la disciplina sigue siendo incipiente, ya que solo hasta la década pasada se comenzaron a generar diagnósticos que permitieran servir como insumo a efecto de promover recomendaciones para dicho sector de las disciplinas sociales. ${ }^{4}$

\footnotetext{
${ }^{4}$ Los estudios existentes con alcance nacional para hablar de la situación de la ciencia política se han mantenido diluidos, en tanto que los datos son agrupados bajo el rubro
} 


\section{EL ESTUDIO}

En esta sección se darán elementos actualizados en relación con el panorama que guarda la disciplina en dos rubros concretos: en primer lugar, se revisa la situación de la oferta docente de la disciplina a nivel nacional en su nivel de licenciatura; posteriormente, se realiza una aproximación puntual a la presencia de las y los profesionales de la disciplina politológica en el marco del Sistema Nacional de Investigadores, bajo la premisa de que solo se toma en cuenta a quienes explícitamente se autoidentifican dentro de la Comisión $\mathrm{V}$ (Ciencias Sociales) bajo el rubro Ciencias Políticas y a la vez se ubican en alguno de los campos que se reconocen dentro de la misma: Vida Política, Sociología de la Política, Instituciones Políticas, Sistemas Políticos, Política Teórica e Ideologías Políticas. ${ }^{5}$

general de «ciencias políticas». Las valoraciones siguen siendo más de tipo subjetivo y de orden general sobre el tipo de líneas de investigación que caracterizan a la disciplina, pero sin algún apoyo analítico o de clasificación más profunda. La primera gran excepción lo sería el trabajo coordinado por Hilda Aburto en 1992 por encargo del CNCPyAP, a efecto de tener un diagnóstico sobre la condición de los programas docentes de licenciatura, cuya metodología sería reproducida en Alarcón Olguín (2OII y 20I2) para detectar las continuidades que mantenía dicho análisis 20 años después. Posteriormente, cabe consignar dos importantes fuentes de estudio, como es el documento de trabajo número I elaborado por el comicip en el año 20I3, mismo que consigna una numeralia sobre la situación de la matrícula de alumnos, programas docentes y acreditados por la ACCECISO existentes en el país, además de indicar el número de investigadores en el SNI en el campo de Ciencias Políticas y su distribución regional siguiendo los criterios de comecso. Otro tanto se puede destacar del trabajo de Vidal de la Rosa (2013). Estos documentos hasta ahora solo han sido retomados por los trabajos de Barrientos del Monte (20I5) y Alarcón Olguín (20I7), a efecto de dar mayor profundidad y seguimiento a las tendencias identificadas dentro de la disciplina, sobre la situación de las revistas, las asociaciones, la oferta docente y la evolución de la comunidad existente en el campo.

${ }^{5}$ Respecto al campo de Ideologías Políticas, cabe indicar que en la muestra analizada que se presenta aquí solo una persona se ubicó en ese rubro, por lo que se le sumó al rubro de Política Teórica. Esta clasificación que aplica el SNI es pertinente resaltarla, porque permite depurar en forma muy precisa, dentro del Padrón de Beneficiarios del programa, el universo de casos a analizar, ya que los separa de los campos de las Relaciones Internacionales, Administración Pública, Políticas Sectoriales, Opinión Pública, Otras Especialidades e, incluso, de la extraña inclusión de la Biblioteconomía y Archivonomía (véase Alarcón Olguín, 20I7). 
Otra decisión metodológica que se tomó para realizar el presente diagnóstico fue adoptar el enfoque de división regional que ha sido empleado tanto por la Asociación Nacional de Universidades e Instituciones de Educación Superior (Anuies) como por el Consejo Mexicano de Ciencias Sociales (COMECso). Este criterio nos servirá como punto de partida para agrupar al conjunto de las instituciones identificadas en donde se ubican los programas de docencia e investigadores vigentes en ciencia política vigentes al año 2020, así como nos dará pauta para clasificar y comparar sus condiciones generales de institucionalización y organización. Las zonas son 6:

- Región Noroeste: Baja California, Baja California Sur, Chihuahua, Sonora y Sinaloa.

- Región Noreste: Coahuila, Durango, Nuevo León, San Luis Potosí, Tamaulipas y Zacatecas.

- Región Centro-Occidente: Aguascalientes, Colima, Guanajuato, Jalisco, Michoacán y Nayarit.

- Región Metropolitana: Ciudad de México y Estado de México.

- Región Centro-Sur: Guerrero, Hidalgo, Morelos, Querétaro, Puebla y Tlaxcala.

- Región Sur-Sureste: Campeche, Chiapas, Oaxaca, Quintana Roo, Tabasco, Veracruz y Yucatán.

Mapa I. Consejos Regionales Anuies-COMECSO.

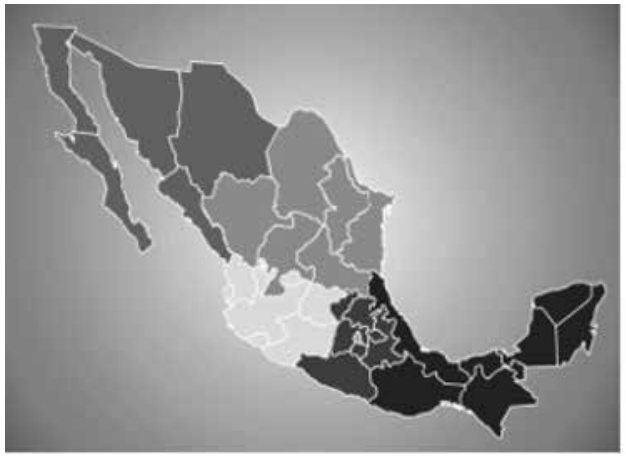

Región Noroeste

Región Noreste

Región Centro-Occidente

Región Metropolitana

Región Centro-Sur

Región Sur-Sureste

Fuente: <http://www.anuiescrne.uadec.mx/wp-content/uploads/2org/o4/INICIO.png>. 
Un elemento que se consideró en el análisis fue la revisión de los padrones de las instituciones educativas afiliadas tanto a la ya referida Anuies como a la Federación de Instituciones Mexicanas Particulares de Educación Superior (FIMPES), que integra a universidades y centros de origen privado, lo cual es importante tener en consideración, debido a que muchos de sus integrantes no pertenecen a la primera asociación. Respecto a la acreditación de los programas de docencia que se imparten a nivel licenciatura, se revisaron los padrones de los Comités Interinstitucionales de Evaluación de la Educación Superior (CIEEs) y del Consejo para la Acreditación de la Educación Superior (COPAEs), poniendo atención de manera específica en las certificaciones otorgadas por la Asociación para la Acreditación y Certificación en Ciencias Sociales (ACCECISO). Para ello, se pudieron reconocer e integrar los programas bajo las siguientes denominaciones:

- Administración Pública y Ciencias Políticas

- Ciencia Política

- Ciencias Políticas y Administración Pública

- Ciencia Política y Gobernanza

- Ciencias Políticas y Gestión Pública

- Ciencias Políticas y Relaciones Internacionales

- Política y Administración Pública

- Política y Gestión Social

\section{PROGRAMAS DE DOCENCIA EN LICENCIATURA}

Un rasgo definitorio que caracteriza la evolución de la ciencia política mexicana en la mayor parte de sus dimensiones institucionales de estudio, al momento de comparar su desempeño regional, es la aparente desconcentración de la oferta docente en el nivel de licenciatura. Esto es, se puede apreciar que ya no existe un predominio formal de la denominada Zona Metropolitana (Ciudad de México y el Estado de México), como se puede advertir en la tabla I, que compara la situación entre 2010 y 2020 : 
Tabla I. Distribución regional y estatal de los programas de licenciatura en Ciencia Politica, años 2010 y 2020

\begin{tabular}{|c|c|c|c|c|c|c|}
\hline \multirow{2}{*}{$\begin{array}{l}\text { Regiones y Estados } \\
\text { Años }\end{array}$} & \multicolumn{2}{|c|}{$\begin{array}{c}\text { Universidad } \\
\text { Publica } \\
\end{array}$} & \multicolumn{2}{|c|}{$\begin{array}{c}\text { Universidad } \\
\text { Privada } \\
\end{array}$} & \multicolumn{2}{|c|}{$\begin{array}{c}\text { Total } \\
\text { Universidades }\end{array}$} \\
\hline & 2010 & 2020 & 2010 & 2020 & 2010 & 2020 \\
\hline Región Centro Occidente & 4 & 9 & 8 & 7 & $\mathrm{I} 2$ & I6 \\
\hline Aguascalientes & $\mathrm{I}$ & 2 & $\mathrm{O}$ & $\mathrm{O}$ & $\mathrm{I}$ & 2 \\
\hline Colima & I & I & $\mathrm{O}$ & $\mathrm{O}$ & $\mathrm{I}$ & I \\
\hline Guanajuato & $\mathrm{O}$ & 2 & $\mathrm{I}$ & 2 & $\mathrm{I}$ & 4 \\
\hline Jalisco & $\mathrm{I}$ & I & 4 & 3 & 5 & 4 \\
\hline Michoacán & $\mathrm{O}$ & 2 & I & I & I & 3 \\
\hline Nayarit & $\mathrm{I}$ & I & 2 & I & 3 & 2 \\
\hline Región Noroeste & 4 & 6 & 3 & 4 & 7 & IO \\
\hline Baja California & I & I & $\mathrm{O}$ & I & I & 2 \\
\hline Baja California Sur & $\mathrm{I}$ & $\mathrm{I}$ & $\mathrm{O}$ & $\mathrm{O}$ & $\mathrm{I}$ & $\mathrm{I}$ \\
\hline Chihuahua & $\mathrm{I}$ & $\mathrm{I}$ & $\mathrm{I}$ & $\mathrm{I}$ & 2 & 2 \\
\hline Sinaloa & $\mathrm{I}$ & 2 & $\mathrm{I}$ & I & 2 & 3 \\
\hline Sonora & $\mathrm{O}$ & $\mathrm{I}$ & $\mathrm{I}$ & $\mathrm{I}$ & $\mathrm{I}$ & 2 \\
\hline Región Noreste & 2 & 5 & 8 & 6 & IO & II \\
\hline Coahuila & $\mathrm{I}$ & $\mathrm{I}$ & I & $\mathrm{O}$ & 2 & $\mathrm{I}$ \\
\hline Durango & $\mathrm{O}$ & I & 2 & $\mathrm{I}$ & 2 & 2 \\
\hline Nuevo León & $\mathrm{I}$ & I & 2 & 2 & 3 & 3 \\
\hline San Luis Potosí & $\mathrm{O}$ & $\mathrm{I}$ & $\mathrm{I}$ & $\mathrm{I}$ & $\mathrm{I}$ & 2 \\
\hline Tamaulipas & $\mathrm{O}$ & $\mathrm{I}$ & I & I & $\mathrm{I}$ & 2 \\
\hline Zacatecas & $\mathrm{O}$ & $\mathrm{O}$ & I & $\mathrm{I}$ & $\mathrm{I}$ & $\mathrm{I}$ \\
\hline Región Centro-Sur & 6 & 6 & 7 & $\mathrm{I} 2$ & $\mathrm{I} 3$ & I8 \\
\hline Guerrero & $\mathrm{I}$ & $\mathrm{I}$ & $\mathrm{I}$ & $\mathrm{I}$ & 2 & 2 \\
\hline Hidalgo & $\mathrm{I}$ & I & $\mathrm{O}$ & 3 & I & 4 \\
\hline Morelos & $\mathrm{O}$ & $\mathrm{I}$ & 2 & 2 & 2 & 3 \\
\hline Puebla & 2 & $\mathrm{I}$ & 3 & 6 & 5 & 7 \\
\hline Querétaro & $\mathrm{I}$ & $\mathrm{I}$ & I & $\mathrm{O}$ & 2 & $\mathrm{I}$ \\
\hline Tlaxcala & $\mathrm{I}$ & $\mathrm{I}$ & $\mathrm{O}$ & $\mathrm{O}$ & $\mathrm{I}$ & $\mathrm{I}$ \\
\hline Región Metropolitana & 8 & 9 & 5 & 8 & $\mathrm{I} 3$ & $\mathrm{I7}$ \\
\hline $\mathrm{DF} / \mathrm{CDMX}$ & 6 & 6 & 4 & 7 & IO & $\mathrm{I} 3$ \\
\hline Estado de México & 2 & 3 & $\mathrm{I}$ & $\mathrm{I}$ & 3 & 4 \\
\hline
\end{tabular}




\begin{tabular}{lcccccc}
\hline Regiones y Estados & \multicolumn{2}{c}{$\begin{array}{c}\text { Universidad } \\
\text { Publica }\end{array}$} & \multicolumn{2}{c}{$\begin{array}{c}\text { Universidad } \\
\text { Privada }\end{array}$} & \multicolumn{2}{c}{$\begin{array}{c}\text { Total } \\
\text { Universidades }\end{array}$} \\
\hline Años & 20I0 & $\mathbf{2 0 2 0}$ & 20I0 & $\mathbf{2 0 2 0}$ & $\mathbf{2 0 I 0}$ & $\mathbf{2 0 2 0}$ \\
\hline Región Sur-Sureste & 5 & 8 & IO & I9 & I5 & 27 \\
\hline Campeche & I & I & O & O & I & I \\
\hline Chiapas & O & I & 3 & 5 & 3 & 6 \\
\hline Oaxaca & I & I & I & 2 & 2 & 3 \\
\hline Quintana Roo & I & I & O & I & I & 2 \\
\hline Tabasco & I & I & I & 2 & 2 & 3 \\
\hline Veracruz & I & 3 & 3 & 7 & 4 & IO \\
\hline Yucatán & O & O & 2 & 2 & 2 & 2 \\
\hline Total nacional & 29 & 43 & $4 \mathrm{I}$ & 56 & 70 & 98 \\
\hline Fuente Elaboracon
\end{tabular}

Fuente: Elaboración propia con datos de Anuies (2010 y 2020) y FIMPES (2020).

Si se observa con detenimiento la tabla, en las diversas regiones resulta factible identificar nodos de influencia, como por ejemplo se destacan en el caso de la región Centro-Occidente las condiciones de predominio que posee el estado de Jalisco (que tiene una buena oferta numérica de instituciones públicas y privadas, aunque con peso importante la Universidad de Guadalajara, junto con El Colegio de Jalisco y el ITESO), seguido por Guanajuato, cuya implantación de su programa de Ciencia Política en las sedes Guanajuato capital y León de su universidad pública estatal a principios de la década pasada vino a rebasar a programas más antiguos como los existentes en estados como Colima, Aguascalientes o Nayarit, los cuales se han mantenido con dinámicas de crecimiento menores derivadas de una falta de competencia interna para dichas universidades públicas estatales que ofrecen la carrera. De manera más incipiente se encuentra el caso de Michoacán, cuyos programas son muy recientes en sus fechas de creación, en espacios interesantes como la Universidad de La Ciénega o la Universidad Indígena Intercultural de Michoacán.

En el caso de la región Noroeste se percibe un desarrollo en apariencia más equilibrado, si bien se destacan por su tradición e influencia los casos de Baja California (UABC) y Chihuahua (UACh y UACJ), dejando en un proceso de más lenta evolución a Baja California Sur y Sinaloa (con programas estatales competentes de bastante antigüedad dentro de la disciplina) y por último a Sonora, en donde formalmente la ciencia política se ha visto sub- 
sumida dentro de la impartición de programas más claramente centrados en el terreno de la administración pública.

La región Noreste, por su parte, tiene como punto de referencia al estado de Nuevo León (donde destacan la UANL y el Tecnológico de Monterrey) y hay casos de mayor debilidad, como los de Coahuila (pese a tener un programa de larga data en la UADEC), Zacatecas (que paradójicamente su universidad estatal [UAZ] tiene una oferta de posgrado muy relevante en la materia, mas no así en el ámbito de la licenciatura, al no impartirla en ese nivel), y finalmente estados como Durango, Tamaulipas y San Luis Potosí, con programas muy mínimos o muy recientes.

$\mathrm{Al}$ acercarnos a la zona Centro Sur, se puede identificar el predominio del estado de Puebla, que posee un conjunto de instituciones públicas y privadas bien identificadas (BUAP, UDLAP, IberoPuebla o la UPAEP) que ofrecen programas docentes de buena calidad, seguida de las entidades como Querétaro, Guerrero e Hidalgo, cuyas universidades estatales han tenido muy buenos avances, dejando en menor grado los casos de Tlaxcala y Morelos.

En el caso de la región Sur-Sureste, puede resaltarse que esta zona ha tenido un crecimiento notable en el número de programas activos en la disciplina. De hecho, es la que hoy agrupa a la mayor cantidad en el país. Pero ciertamente sus condiciones son aún precarias en la mayor parte de los casos, además de que buena parte de dichos programas son integrados por matrículas reducidas, poseen esquemas semipresenciales o a distancia y ofrecen titulaciones en lapsos menores al promedio nacional. En este caso, la entidad que ha tomado una delantera importante es el estado de Veracruz, seguida de Chiapas, Oaxaca y Quintana Roo. Un caso aparte es el de Campeche, cuya universidad estatal tiene mucha antigüedad, al igual que lo experimentado en Tabasco, donde se ofrece el programa, aunque no en la capital del estado, lo cual explica su falta de crecimiento, mientras en entidades como Yucatán la oferta es apenas cubierta por instituciones privadas.

Por último, la Zona Metropolitana (que incluye a la Ciudad de México y el Estado de México) posee una clara ventaja al disponer de la mayor cantidad de recursos, integrantes en los diversos sistemas de investigación, si bien la cantidad nominal de programas ha permanecido estable durante los años recientes. En este caso, el peso de las instituciones públicas y privadas existentes habla por sí mismo, pero puede hablarse por separado de las uni- 
versidades públicas masivas como la UNAM (FCPys, FES-Acatlán y sus institutos de investigación), la UAM (con sus cinco unidades) y la UACM (con sus cuatro planteles), mientras que por otra parte tenemos a los centros públicos de investigación como el COLMEX, el CIDE, la FLACSO, mientras que dentro de las instituciones privadas se tiene al ITAM, la Universidad Iberoamericana y el Tecnológico de Monterrey. Y para el caso mexiquense, hay una presencia dominante a cargo de la UAEM desde sus diversos planteles (FCPys-Toluca, Amecameca, Texcoco y Zumpango).

Aquí de manera somera podemos señalar que, comparando los datos ofrecidos por el COMICIP en 20I3, había 33 programas que poseían algún tipo de acreditación, sea por parte de los CIEES, ACCECISO o CACECA. En 2020 se pudo ubicar que el número se coloca en 32, siendo casi las mismas instituciones las que mantienen dichas evaluaciones. Explicar este estancamiento no es un asunto menor, ya que intervienen dos factores: primero, el costo económico que implica realizar dichas acreditaciones, cuestión que no toda institución tiene los medios para hacerlo; segundo, existen limitaciones para proveer la información sustantiva que garantice la presencia de programas actualizados, tener la infraestructura y apoyos pertinentes, además de que se disponga del personal idóneo para impartirlos. Esto ha derivado en una falsa cultura de la resistencia y la defensa de la autonomía de los programas ante la intervención e injerencia de dichas instancias externas como los CIEEs, la COPAES y la ACCECISO, lo cual igualmente impacta en un retraso relevante en cuanto a promover acciones y políticas que puedan precisamente estar enfocadas al mejoramiento de dichos programas de estudio.

\section{INVESTIGACIÓN}

Como se mencionó, el acercamiento para valorar la presencia y el desarrollo de la disciplina politológica en México se ha venido sustentando a partir de la distribución e identificación de las y los investigadores adscritos a las instituciones de educación superior públicas y privadas que participan en el Sistema Nacional de Investigadores del Conacyt. El universo de partida es la membresía que siendo integrante del área V (Ciencias Sociales) ubica su campo disciplinario en lo que se denomina Ciencias Políticas. Con esta clasificación inicial, se puede hacer una primera lectura comparativa de 778 
personas respecto a la evolución general en este ámbito, como la que se presenta a continuación en la tabla 2, pero señalando que aquí los números agrupan a especialidades (además de la ciencia política) como las relaciones internacionales, la administración pública, la comunicación (opinión pública) y otras sin identificar.

$\mathrm{Al}$ igual que en el caso de los programas de docencia, aquí se emprendió la revisión general de los padrones de beneficiarios del SNI para los años 20I2, 20I5 y 2020, acomodándolos conforme a la entidad de origen y región académica, además de ubicar su género, cuestión que se pudo hacer para las muestras de los años 2015 y 2020. ${ }^{6}$ El análisis comparativo por regiones nos muestra una clara correspondencia con el factor de consolidación con que se encuentran las entidades que destacan en las zonas analizadas para el caso de la docencia. Así, nuevamente puede verse el liderazgo de entidades como Jalisco para la región Centro-Occidente, Baja California para la región Noroeste, Nuevo León para la zona Noreste, mientras que Puebla lidera la zona Centro-Sur y Oaxaca lo hace en el caso de la zona Sur-Sureste. Resulta explicativo por sí mismo el caso de la región Metropolitana. Otro elemento que se debe destacar es que los números globales crecieron en forma consistente, pasando de 460 investigadores en 20I2, a 549 en 2015 , así como a 778 en 2020 , aunque igualmente se debe advertir que la brecha y proporción entre géneros no ha disminuido, sino que en los hechos se ha ahondado, lo cual implica un elemento de fondo que debe alentar por sí mismo a la generación de un conjunto de acciones significativas para corregir esta situación.

Tabla 2. Distribución regional y estatal de la membresía del sIN en el campo de Ciencias Políticas (CP, AP, RI, CC y otros). Años 20I2, 2015 y 2020

\begin{tabular}{lcccccccc}
\hline \multirow{2}{*}{ Regiones y estados } & \multicolumn{3}{c}{$\begin{array}{c}\text { Número total de } \\
\text { Investigadores/as }\end{array}$} & H & M & H & M \\
\cline { 3 - 8 } & $\mathbf{2 0 1 2}$ & $\mathbf{2 0 1 5}$ & $\mathbf{2 0 2 0}$ & $\mathbf{2 0 1 5}$ & \multicolumn{2}{c}{$\mathbf{2 0 2 0}$} \\
\hline Ańos & 33 & 63 & I00 & 56 & 7 & 74 & 26 \\
\hline Región Centro Occidente & 2 & 6 & I4 & 6 & O & I2 & 2 \\
\hline Aguascalientes & 2 & 3 & 3 & 2 & I & I & 2 \\
\hline Colima & & & & & & &
\end{tabular}

\footnotetext{
${ }^{6}$ Para el caso de los datos de 20I5, se tomó en consideración el trabajo de Barrientos del Monte (2015).
} 


\begin{tabular}{|c|c|c|c|c|c|c|c|}
\hline \multirow{4}{*}{$\begin{array}{l}\text { Regiones y estados } \\
\text { Ańos } \\
\text { Guanajuato } \\
\end{array}$} & \multirow{2}{*}{\multicolumn{3}{|c|}{$\begin{array}{l}\text { Número total de } \\
\text { Investigadores/as }\end{array}$}} & \multicolumn{4}{|c|}{ Género } \\
\hline & & & & $\mathbf{H}$ & $\mathbf{M}$ & $\mathbf{H}$ & $\mathbf{M}$ \\
\hline & 2012 & 2015 & 2020 & \multicolumn{2}{|c|}{2015} & \multicolumn{2}{|c|}{2020} \\
\hline & 6 & II & I8 & 9 & 2 & I4 & 4 \\
\hline Jalisco & 19 & 37 & 58 & 33 & 4 & 42 & I6 \\
\hline Michoacán & 3 & 5 & 6 & 5 & $\mathrm{O}$ & 4 & 2 \\
\hline Nayarit & I & I & I & I & $\mathrm{O}$ & I & $\mathrm{O}$ \\
\hline Región Noroeste & 32 & 43 & 55 & 33 & IO & 34 & $2 \mathrm{I}$ \\
\hline Baja California & I4 & I7 & 22 & I3 & 4 & $\mathrm{I3}$ & 9 \\
\hline Baja California Sur & 2 & $\mathrm{O}$ & $\mathrm{O}$ & $\mathrm{O}$ & $\mathrm{O}$ & $\mathrm{O}$ & $\mathrm{O}$ \\
\hline Chihuahua & 4 & $\mathrm{I} 3$ & I4 & IO & 3 & IO & 4 \\
\hline Sinaloa & IO & 6 & 9 & 4 & 2 & 3 & 6 \\
\hline Sonora & 2 & 7 & IO & 6 & I & 8 & 2 \\
\hline Región Noreste & 27 & 34 & 53 & 24 & IO & 34 & I9 \\
\hline Coahuila & 2 & $\mathrm{O}$ & $\mathrm{O}$ & $\mathrm{O}$ & $\mathrm{O}$ & $\mathrm{O}$ & $\mathrm{O}$ \\
\hline Durango & I & $\mathrm{O}$ & $\mathrm{I}$ & $\mathrm{O}$ & $\mathrm{O}$ & $\mathrm{I}$ & $\mathrm{O}$ \\
\hline Nuevo León & $\mathrm{I} 4$ & 17 & 32 & IO & 7 & $2 \mathrm{I}$ & II \\
\hline San Luis Potosí & 6 & 9 & 7 & 8 & I & 4 & 3 \\
\hline Tamaulipas & I & 2 & 9 & 2 & O & 8 & $\mathrm{I}$ \\
\hline Zacatecas & 3 & 6 & 4 & 4 & 2 & $\mathrm{O}$ & 4 \\
\hline Región Centro-Sur & $4 \mathrm{I}$ & $5 \mathrm{I}$ & 82 & 37 & $\mathrm{I} 4$ & 56 & 26 \\
\hline Guerrero & 3 & 2 & 6 & $\mathrm{I}$ & $\mathrm{I}$ & 3 & 3 \\
\hline Hidalgo & 7 & 4 & I3 & 2 & 2 & 7 & 6 \\
\hline Morelos & 4 & 4 & 9 & 3 & I & 7 & 2 \\
\hline Puebla & 20 & $3 \mathrm{I}$ & $4 \mathrm{I}$ & 23 & 8 & 33 & 8 \\
\hline Querétaro & 5 & 7 & IO & 6 & $\mathrm{I}$ & 6 & 4 \\
\hline Tlaxcala & 2 & 3 & 3 & 2 & $\mathrm{I}$ & $\mathrm{O}$ & 3 \\
\hline Región Metropolitana & 304 & 317 & 380 & $2 \mathrm{II}$ & 106 & 245 & I35 \\
\hline DF/CDMX & 275 & 279 & 330 & $\mathrm{I} 78$ & IOI & 207 & $\mathrm{I} 23$ \\
\hline Estado de México & 29 & 38 & 50 & 33 & 5 & 38 & $\mathrm{I} 2$ \\
\hline Región Sur-Sureste & 17 & 26 & 42 & 20 & 6 & 29 & $\mathrm{I} 3$ \\
\hline Campeche & 2 & $\mathrm{O}$ & $\mathrm{I}$ & $\mathrm{O}$ & $\mathrm{O}$ & $\mathrm{I}$ & $\mathrm{O}$ \\
\hline Chiapas & 2 & 5 & 8 & 4 & $\mathrm{I}$ & 6 & 2 \\
\hline Oaxaca & 2 & 6 & $\mathrm{I} 2$ & 5 & I & 9 & 3 \\
\hline Quintana Roo & 3 & 5 & 5 & 3 & 2 & 4 & I \\
\hline Tabasco & I & $\mathrm{O}$ & 3 & $\mathrm{O}$ & $\mathrm{O}$ & $\mathrm{O}$ & 3 \\
\hline Veracruz & 5 & 8 & 8 & 6 & 2 & 7 & I \\
\hline
\end{tabular}




\begin{tabular}{lcccccccc}
\hline \multirow{2}{*}{ Regiones y estados } & \multicolumn{2}{c}{$\begin{array}{c}\text { Número total de } \\
\text { Investigadores/as }\end{array}$} & \multicolumn{5}{c}{ Género } \\
\cline { 3 - 8 } Años & $\mathbf{2 0 1 2}$ & $\mathbf{2 0 1 5}$ & $\mathbf{2 0 2 0}$ & $\mathbf{2 0 1 5}$ & $\mathbf{2 0 2 0}$ \\
\hline Yucatán & 2 & 2 & 5 & 2 & 0 & 2 & 3 \\
\hline Exterior / Sin institución & 6 & I5 & 66 & 9 & 6 & 36 & 30 \\
\hline Total Nacional & 460 & 549 & 778 & 390 & 159 & 508 & 271 \\
\hline
\end{tabular}

Fuente: Elaboración propia, con base en los datos de los padrones de beneficiarios del SNI para los años 2015 y 2020, los cuales permitieron realizar la estadística comparativa entre géneros para ambos años. Para el año 2012 se tomó en cuenta la estadística básica del SNI de dicho año, pero la cual no hace un desglose exhaustivo por género. Se resalta en negrita para cada región (exceptuando por razones obvias al área metropolitana, al estado que posee mayor presencia de investigadores/as.

A efecto de profundizar en el análisis, se presenta a continuación la tabla 3, en donde condensa la distribución concreta de la membresía del sNi que dentro del segmento disciplinario de Ciencias Políticas se manifestó como especialista en alguno de los cinco campos asociados con la politología en sentido estricto. Para ello, se emplean nuevamente los criterios de ubicación regional señalados por comecso y gracias al uso del Padrón de Beneficiarios 2020 se pudo identificar y reducir la muestra a zIO practicantes de la disciplina, lo cual contrasta con el dato que se había obtenido en una revisión anterior (Alarcón Olguín, 20I7), correspondiente al año 20II, en donde se pudieron identificar a 124 personas, lo cual de entrada muestra que dicho periodo ha experimentado un crecimiento notable, signo de que el despliegue de nuevos programas docentes a lo largo del territorio nacional, así como una mayor participación y producción de calidad en materia de libros, artículos y medios, generan una imagen positiva alrededor del gremio, así como un reconocimiento más puntual y diferenciado de la disciplina respecto a cómo se le percibía en el pasado.

Ahora bien, la muestra nos permite indicar la existencia de una serie muy precisa de problemáticas que no son exclusivas del campo disciplinario, sino que aquejan a las ciencias sociales mexicanas en su conjunto. Destaca de manera significativa el alto nivel de concentración que mantiene la Región Metropolitana (Ciudad de México) respecto al número total de integrantes: I69 de 3 Io (en donde, desde luego, sobresale el predominio de instituciones 
ya referidas como la Unam, el CIDE, el COLMEX y la UAM, solo seguida de manera muy lejana por las zonas Centro Sur con 35 integrantes (encabezada por Puebla con I4, la mayoría ubicados en la BUAP) y la Centro-Occidente con 33 (liderada por el estado de Jalisco con I5 integrantes, mayormente adscritos a la Universidad de Guadalajara, aunque seguida no muy lejos por la Universidad de Guanajuato con Io), mientras que en los estratos intermedios se pueden ubicar las regiones Noreste con I8 (de los cuales destaca Nuevo León con I2, la mayoría de ellos ubicados en la UANL) y la Noroeste también con 18 miembros (donde Baja California y Chihuahua se reparten 8 distinciones cada una, con la UABC y la UACH encabezando estas zonas). Y en los estratos inferiores se encuentra la región Sur-Sureste con apenas Io distinciones (donde las entidades que tienen presencia son Veracruz y Oaxaca). Adicionalmente, se consigna un bloque de 27 integrantes que abarca a personas residentes en el exterior (3) o que declaran estar momentáneamente sin institución (24).

Otro indicador muy alarmante es que a pesar de que en varios estados de la república hay instituciones de educación superior de larga data impartiendo la carrera en el contexto docente, resulta significativo que no tengan politólogas o politólogos como tales que posean la membresía del SNI, cuestión interesante porque ello remite a pensar que muchos investigadores participantes en dichos programas señalan identificaciones o adscripciones a otras disciplinas adyacentes. Bajo esta condición, tenemos que entidades como Baja California Sur, Coahuila, Durango, Campeche, Nayarit, Quintana Roo ni Tabasco poseen ningún integrante. Y en un rango de I a 4 integrantes se ubican Aguascalientes, Colima y Michoacán en la zona Centro-Occidente; Sinaloa y Sonora en la zona Noroeste; San Luis Potosí, Tamaulipas y Zacatecas en la zona Noreste; Hidalgo, Morelos y Tlaxcala en el área Centro Sur, mientras que Chiapas, Yucatán, Oaxaca y Veracruz están en dicha situación en la región Sur-Sureste. Esto revela un punto de notoria debilidad y desfase en dichas entidades, por cuanto se tiene una presencia e incluso hay un crecimiento nominal de programas docentes, pero ello no va acompañado del establecimiento de condiciones óptimas para el desarrollo de una cultura de la investigación de alto nivel como la que demanda el SNI.

El segundo aspecto que resulta notable identificar en la tabla 3 se refiere a la notoria diferencia entre la participación entre géneros: 218 hombres y solo 92 mujeres. Esta diferencia se revela mucho más significativa cuan- 
do se van recorriendo los diversos niveles de las distinciones. Por ejemplo, cabe advertir con sorpresa que solo hay académicas mujeres en la Región Metropolitana con nivel III (cinco investigadoras, todas pertenecientes a instituciones de la Ciudad de México) y solo i6 con nivel ir: is residentes en la capital del país y una adscrita al ITESM-Estado de México). Fuera de la zona metropolitana únicamente se pudo identificar una investigadora en la región Centro-Sur, en el estado de Guerrero, con nivel iı. En ninguna de las demás regiones del país existen politólogas con reconocimiento en los niveles II y III, algo sin duda inusitado considerando que el crecimiento nominal ha existido, pero implica un tema relevante dedicar esfuerzos para promover una suerte de task forcé, similar a la realizada por la APSA en Estados Unidos y algunas asociaciones politológicas europeas, para encarar este problema y diseñar acciones puntuales que ayuden a erradicar este fenómeno en el menor tiempo posible.

Tabla 3. Distribución de la membresía del SNI (Ciencia Politica exclusivamente) por nivel, regiones y entidades federativas, 2020

\begin{tabular}{|c|c|c|c|c|c|c|c|c|}
\hline \multirow{2}{*}{$\begin{array}{l}\text { Género } \\
\text { Nivel SNI }\end{array}$} & \multicolumn{4}{|c|}{ Hombres } & \multicolumn{4}{|c|}{ Mujeres } \\
\hline & $\mathrm{C}$ & I & 2 & 3 & $\mathrm{C}$ & I & 2 & 3 \\
\hline \multicolumn{9}{|l|}{$\mathrm{RCO}=33$} \\
\hline $\mathrm{H}=23 / \mathrm{M}=\mathrm{IO}$ & 5 & $\mathrm{I} 3$ & 3 & 2 & 6 & 4 & 0 & $\mathrm{O}$ \\
\hline Ags $=3$ & 2 & I & $\mathrm{O}$ & $\mathrm{O}$ & $\mathrm{O}$ & $\mathrm{O}$ & $\mathrm{O}$ & $\mathrm{O}$ \\
\hline $\mathrm{Col}=\mathrm{I}$ & $\mathrm{O}$ & $\mathrm{O}$ & $\mathrm{O}$ & $\mathrm{O}$ & $\mathrm{O}$ & I & $\mathrm{O}$ & $\mathrm{O}$ \\
\hline Gto $=\mathrm{IO}$ & $\mathrm{O}$ & 5 & I & I & 2 & I & $\mathrm{O}$ & $\mathrm{O}$ \\
\hline $\mathrm{Jal}=\mathrm{I} 5$ & 2 & 5 & 2 & I & 3 & 2 & 0 & $\mathrm{O}$ \\
\hline Mich $=4$ & I & 2 & O & $\mathrm{O}$ & I & $\mathrm{O}$ & 0 & $\mathrm{O}$ \\
\hline $\mathrm{Nay}=\mathrm{O}$ & $\mathrm{O}$ & $\mathrm{O}$ & $\mathrm{O}$ & 0 & $\mathrm{O}$ & $\mathrm{O}$ & $\mathrm{O}$ & $\mathrm{O}$ \\
\hline \multicolumn{9}{|l|}{$\mathrm{RNO}=\mathrm{I} 8$} \\
\hline $\mathrm{H}=\mathrm{I} 4 / \mathrm{M}=4$ & 4 & 6 & 4 & 0 & I & 3 & 0 & $\mathrm{O}$ \\
\hline $\mathrm{BC}=8$ & 2 & I & 2 & $\mathrm{O}$ & I & 2 & 0 & $\mathrm{O}$ \\
\hline $\mathrm{BCS}=\mathrm{O}$ & $\mathrm{O}$ & 0 & 0 & $\mathrm{O}$ & 0 & 0 & $\mathrm{O}$ & $\mathrm{O}$ \\
\hline Chih $=8$ & $\mathrm{O}$ & 5 & 2 & $\mathrm{O}$ & $\mathrm{O}$ & I & $\mathrm{O}$ & $\mathrm{O}$ \\
\hline $\operatorname{Sin}=I$ & I & $\mathrm{O}$ & $\mathrm{O}$ & $\mathrm{O}$ & $\mathrm{O}$ & $\mathrm{O}$ & $\mathrm{O}$ & $\mathrm{O}$ \\
\hline Son = I & $\mathrm{I}$ & $\mathrm{O}$ & $\mathrm{O}$ & $\mathrm{O}$ & $\mathrm{O}$ & $\mathrm{O}$ & 0 & $\mathrm{O}$ \\
\hline \multicolumn{9}{|l|}{$\mathrm{RNE}=\mathrm{I} 8$} \\
\hline $\mathrm{H}=\mathrm{I} 3 / \mathrm{M}=5$ & 5 & 7 & I & O & 2 & 3 & $\mathrm{O}$ & $\mathrm{O}$ \\
\hline
\end{tabular}




\begin{tabular}{|c|c|c|c|c|c|c|c|c|}
\hline \multirow{2}{*}{$\begin{array}{ll} & \text { Género } \\
\text { Coah }=0\end{array}$} & \multicolumn{4}{|c|}{ Hombres } & \multicolumn{4}{|c|}{ Mujeres } \\
\hline & $\mathrm{O}$ & $\mathrm{O}$ & $\mathrm{O}$ & $\mathrm{O}$ & $\mathrm{O}$ & $\mathrm{O}$ & $\mathrm{O}$ & $\mathrm{O}$ \\
\hline Dgo $=0$ & $\mathrm{O}$ & 0 & $\mathrm{O}$ & $\mathrm{O}$ & $\mathrm{O}$ & $\mathrm{O}$ & $\mathrm{O}$ & $\mathrm{O}$ \\
\hline $\mathrm{NL}=\mathrm{I} 2$ & 5 & 5 & 0 & 0 & 0 & 2 & 0 & O \\
\hline$S L P=2$ & $\mathrm{O}$ & I & I & $\mathrm{O}$ & $\mathrm{O}$ & $\mathrm{O}$ & $\mathrm{O}$ & $\mathrm{O}$ \\
\hline Tamps $=2$ & $\mathrm{O}$ & I & $\mathrm{O}$ & $\mathrm{O}$ & I & $\mathrm{O}$ & $\mathrm{O}$ & $\mathrm{O}$ \\
\hline $\mathrm{Zac}=2$ & $\mathrm{O}$ & 0 & 0 & $\mathrm{O}$ & I & I & $\mathrm{O}$ & $\mathrm{O}$ \\
\hline \multicolumn{9}{|l|}{$\mathrm{RCS}=35$} \\
\hline $\mathrm{H}=22 / \mathrm{M}=\mathrm{I} 3$ & 3 & $\mathrm{I} 2$ & 6 & $\mathrm{I}$ & 4 & 8 & I & $\mathrm{O}$ \\
\hline Gro $=5$ & I & $\mathrm{O}$ & I & $\mathrm{O}$ & $\mathrm{O}$ & 2 & I & $\mathrm{O}$ \\
\hline $\mathrm{Hgo}=3$ & $\mathrm{O}$ & 3 & $\mathrm{O}$ & $\mathrm{O}$ & $\mathrm{O}$ & $\mathrm{O}$ & $\mathrm{O}$ & $\mathrm{O}$ \\
\hline Mor $=4$ & $\mathrm{I}$ & $\mathrm{O}$ & $\mathrm{I}$ & $\mathrm{I}$ & $\mathrm{O}$ & $\mathrm{I}$ & $\mathrm{O}$ & $\mathrm{O}$ \\
\hline Pue $=\mathrm{I} 4$ & $\mathrm{I}$ & 7 & 3 & $\mathrm{O}$ & $\mathrm{I}$ & 2 & $\mathrm{O}$ & $\mathrm{O}$ \\
\hline Qro $=6$ & $\mathrm{O}$ & 2 & I & $\mathrm{O}$ & I & 2 & $\mathrm{O}$ & $\mathrm{O}$ \\
\hline Tlax =3 & $\mathrm{O}$ & $\mathrm{O}$ & $\mathrm{O}$ & $\mathrm{O}$ & 2 & $\mathrm{I}$ & $\mathrm{O}$ & $\mathrm{O}$ \\
\hline \multicolumn{9}{|l|}{$\mathrm{RM}=\mathrm{I} 69$} \\
\hline $\mathrm{H}=\mathrm{I} 2 \mathrm{I} / \mathrm{M}=48$ & I6 & 60 & 27 & I8 & II & 16 & 16 & 5 \\
\hline $\mathrm{DF} / \mathrm{CDMX}=\mathrm{I} 53$ & $\mathrm{I} 4$ & 47 & 27 & I8 & II & I6 & 15 & 5 \\
\hline EdoMéx =I6 & 2 & $\mathrm{I} 3$ & $\mathrm{O}$ & $\mathrm{O}$ & $\mathrm{O}$ & $\mathrm{O}$ & $\mathrm{I}$ & $\mathrm{O}$ \\
\hline \multicolumn{9}{|l|}{$\mathrm{RSS}=\mathrm{IO}$} \\
\hline $\mathrm{H}=9 / \mathrm{M}=\mathrm{I}$ & $\mathrm{I}$ & 6 & 2 & $\mathrm{O}$ & I & $\mathrm{O}$ & $\mathrm{O}$ & $\mathrm{O}$ \\
\hline Camp $=0$ & $\mathrm{O}$ & $\mathrm{O}$ & $\mathrm{O}$ & $\mathrm{O}$ & $\mathrm{O}$ & $\mathrm{O}$ & $\mathrm{O}$ & $\mathrm{O}$ \\
\hline Chis $=2$ & $\mathrm{I}$ & I & $\mathrm{O}$ & $\mathrm{O}$ & $\mathrm{O}$ & $\mathrm{O}$ & $\mathrm{O}$ & $\mathrm{O}$ \\
\hline $\mathrm{Oax}=3$ & $\mathrm{O}$ & 2 & $\mathrm{O}$ & $\mathrm{O}$ & $\mathrm{I}$ & $\mathrm{O}$ & $\mathrm{O}$ & $\mathrm{O}$ \\
\hline $\mathrm{QROO}=\mathrm{O}$ & $\mathrm{O}$ & $\mathrm{O}$ & $\mathrm{O}$ & $\mathrm{O}$ & $\mathrm{O}$ & $\mathrm{O}$ & $\mathrm{O}$ & $\mathrm{O}$ \\
\hline $\mathrm{Tab}=\mathrm{O}$ & $\mathrm{O}$ & $\mathrm{O}$ & $\mathrm{O}$ & $\mathrm{O}$ & $\mathrm{O}$ & $\mathrm{O}$ & $\mathrm{O}$ & $\mathrm{O}$ \\
\hline Ver $=4$ & $\mathrm{O}$ & 2 & 2 & $\mathrm{O}$ & $\mathrm{O}$ & $\mathrm{O}$ & $\mathrm{O}$ & $\mathrm{O}$ \\
\hline Yuc $=\mathrm{I}$ & $\mathrm{O}$ & I & $\mathrm{O}$ & $\mathrm{O}$ & $\mathrm{O}$ & $\mathrm{O}$ & $\mathrm{O}$ & $\mathrm{O}$ \\
\hline $\begin{array}{l}\text { Ext } / \mathrm{NI}=28 \\
\mathrm{H}=\mathrm{I} 6 \mathrm{M}=\mathrm{I} 2\end{array}$ & 8 & 8 & $\mathrm{O}$ & $\mathrm{O}$ & 4 & 6 & 2 & $\mathrm{O}$ \\
\hline Ext $=3$ & $\mathrm{O}$ & I & $\mathrm{O}$ & $\mathrm{O}$ & 2 & $\mathrm{O}$ & $\mathrm{O}$ & $\mathrm{O}$ \\
\hline $\mathrm{NI}=25$ & 8 & 7 & $\mathrm{O}$ & $\mathrm{O}$ & 2 & 6 & 2 & $\mathrm{O}$ \\
\hline $\begin{array}{l}\text { Total } \\
\text { Nacional = 3IO } \\
\mathrm{H}=2 \mathrm{I} 8 / \mathrm{M}=92\end{array}$ & 42 & II 2 & 43 & $2 \mathrm{I}$ & 29 & 40 & I9 & 5 \\
\hline & \multicolumn{4}{|c|}{218} & \multicolumn{4}{|c|}{92} \\
\hline
\end{tabular}


Fuente: Elaboración propia, con datos del Padrón de Beneficiarios del SIN-2020. Disponible para descarga en la sección Archivo Histórico SNI en la página del Conacyt: <https://www.conacyt. gob.mx/Archivo-Hist\%C3\%B3rico.html>.

El tercer aspecto que se revisó en la base de datos -y que se muestra en la tabla 4- corresponde a ubicar la orientación temática mostrada por el conjunto de integrantes de la comunidad politológica, que se recuperó a partir de las seis subespecialidades que reconoce el SNI para el campo concreto de la disciplina, como lo son Vida Política (la cual abarca el estudio de los temas electorales, comportamiento político, partidos, movimientos, grupos de poder y liderazgos); Sociología de la Política (interesada en temas como las cuestiones étnicas, religiosas, derechos políticos, grupos sociales, conflictos); Instituciones Políticas (que estudia los poderes Ejecutivo, Legislativo y Judicial, así como las relaciones entre los mismos), Política Teórica e Ideologías Políticas (aquí agrupadas en un solo campo, que pueden abarcar desde temas filosóficos o histórico-conceptuales hasta los de índole metodológica), y finalmente está el campo de Sistemas Políticos (que remite concretamente al estudio de la política comparada, así como el estudio de los regímenes políticos),

Tabla 4. Distribución de la membresía SNI (Ciencia Politica exclusivamente) por subespecialidad, nivel y género (2020)

\begin{tabular}{lccccccccccc}
\hline $\begin{array}{l}\text { Área de } \\
\text { Subespecialidad }\end{array}$ & $\begin{array}{c}\text { Vida } \\
\text { Política }\end{array}$ & $\begin{array}{c}\text { Sociología } \\
\text { de la Política }\end{array}$ & $\begin{array}{c}\text { Institucio- } \\
\text { nes Políticas }\end{array}$ & $\begin{array}{c}\text { Política Teórica } \\
\text { / Ideologías } \\
\text { Políticas }\end{array}$ & $\begin{array}{c}\text { Sistemas } \\
\text { Políticos }\end{array}$ \\
\hline $\begin{array}{l}\text { Género } \\
\text { Nivel SNI }\end{array}$ & H & M & H & M & H & M & H & M & H & M \\
\hline C=7I & I2 & 6 & II & II & 7 & 6 & 5 & 3 & 7 & 3 \\
\hline I= I52 & 39 & I2 & I8 & I4 & 27 & IO & I9 & O & 9 & 4 \\
\hline 2=62 & I3 & 6 & I2 & 4 & 9 & 7 & 5 & I & 4 & I \\
\hline $3=26$ & 4 & 2 & 3 & 2 & 6 & I & 4 & O & 4 & O \\
\hline $\begin{array}{l}\text { Subtotales } \\
\text { por género }\end{array}$ & 68 & 26 & 44 & 3 I & 49 & 24 & 33 & 4 & 24 & 8 \\
\hline $\begin{array}{l}\text { Total Nacional = 3IO } \\
\text { H=2I8 M=92 }\end{array}$ & 94 & & 75 & & 73 & & 37 & & 32 \\
\hline
\end{tabular}


Fuente: Elaboración propia, con datos del Padrón de Beneficiarios del SIN-2020. Disponible para descarga en la sección Archivo Histórico SNI en la página del Conacyt: <https://www.conacyt. gob.mx/Archivo-Hist\% $\mathrm{C}_{3} \%$ B3rico.htmls.

Como puede advertirse en la tabla 4, el campo de Vida Política es el más nutrido, comprensible por el peso significativo que cobraron los procesos electorales y el estudio de las organizaciones partidarias, a partir de los procesos de reformas política y transición a la democracia, lo que se manifiesta precisamente en que los dos siguientes campos más reconocidos sean justamente el de Sociología de la Política e Instituciones Políticas, mismos que sin duda obligan al estudio de los impactos en materia de (re)diseño constante de las acciones propias del Estado y de la sociedad a partir de la presencia de los actores sociales y grupos de presión que interactúan en los procesos de negociación y toma de decisiones, tanto en los espacios de la gestión y el gobierno, como en la interacción propiamente dicha que se presenta en el devenir político diario. Y, finalmente, se pueden ubicar quienes están interesados en realidad en estudios de corte teórico, filosófico, histórico o metodológico en torno a la naturaleza misma de la disciplina, la cual tiene una cantidad similar de practicantes respecto a quienes se colocan en el terreno de los sistemas políticos, cuyo énfasis, desde luego, no solo abarcaría la percepción tradicional de trabajar los estudios de caso para comparar a México con uno o más países, sino que también ahora podemos situar allí la ruta por la cual se desarrollan estudios de esa naturaleza, pero ahora en el plano subnacional.

Desde luego, es importante resaltar que queda mucho por hacer para generar estudios más detallados sobre los procesos de movilidad y trayectorias experimentados por la comunidad politológica, como por ejemplo ver la velocidad con que se alcanzan niveles más altos en las distinciones, identificar el predominio y concentración de las distinciones más altas en ciertas instituciones, así como ir a una revisión más detallada acerca de las características de la producción académica global que presenta la disciplina a través de dichos exponentes. 


\section{REFLEXIONES FINALES. LA CIENCIA POLÍTICA MEXICANA: ¿HACIA DÓNDE DEBERÍAMOS IR?}

La ciencia política mexicana, sin duda, puede ser defendida como existente en función de sus números básicos, así como en términos de su producción académica, la diversidad y amplitud con que se puede condensar la salida de artículos y libros, a partir del número creciente de instituciones académicas públicas y sobre todo privadas que ahora la imparten, aunque ciertamente en condiciones muchas veces cuestionables respecto a sus contenidos y el personal que se emplea para ello, así como por la cantidad de personas que precisamente egresan de sus niveles de licenciatura, especialización o posgrado.

Se puede hablar de textos y enfoques que se han instaurado como buenos ejemplos de tradiciones desde las cuales podemos identificar nuestras propias mesas separadas, y de cómo hemos recorrido problemas, como la discusión de la calidad de la democracia y el desarrollo político, así como la revisión permanente de las instituciones de poder y de gobierno; la discusión perenne entre democracia versus autoritarismo, ahora trasladada al complejo tema del neopopulismo, mismo que ha dado, a su vez, renovado bríos al dilema de la confrontación interminable y cíclica entre el nacionalismo revolucionario versus el neoliberalismo. Tampoco puede pasarse por alto la ruta marcada por la oposición clásica del pensamiento marxista ante los enfoques institucional y sistémico, así como las lecturas actuales sobre el posmodernismo, los estudios de corte multicultural y los asociados con la introducción de la perspectiva de género. Y como se mencionó también, no se puede omitir el proceso persistente que se ha dado con la introducción de los instrumentos técnicos, como el uso de software computacional y paquetes estadísticos cada vez más sofisticados, que van dirigidos a modelar, procesar o presentar importantes cúmulos de información tanto de orden cualitativo como cuantitativo, a efecto de sustentar en forma lo más robusta posible la construcción de casos e investigaciones a partir de la construcción de conceptos, la operacionalización de variables y la comprobación de hipótesis, en tanto una suerte de canon metodológico que poco a poco ha ido permeando dentro de los propios subcampos de la disciplina. 
Desde el punto de vista metodológico, también cabe destacar el avance creciente de la interdisciplina y la generación de subcampos convergentes de interacción dentro del medio profesional, mismos que han logrado crecer gracias a la necesidad de entender los modelos de gobierno mediante diseños de investigación más complejos e interdependientes dentro y fuera de sus fronteras normativas e incluso técnicas. Por desgracia, para los alcances de este trabajo, hacer una revisión a profundidad de estos asuntos en materia de valorar las innovaciones, y el cambio conceptual experimentado por la disciplina escapa a las posibilidades de uno por cuestiones de extensión, pero sin duda representa un ejercicio muy necesario a ser realizado, a efecto de situar cuáles son los impactos que las agendas de investigación tienen a partir de su adopción.

La exigencia para que la ciencia política mexicana responda en un sentido práctico (y no solo teórico) a las exigencias de vivir en un entorno viable con ciertos atributos concretos, ha requerido no solo de contar con estructuras eficaces en las áreas más usuales de gestión y respuesta para recomendar mejores decisiones y políticas académicas en las instituciones de educación superior, sino además ha demandado crear y contender con las exigencias de nuevos segmentos poblacionales que demandan reconocimiento, acceso y ejercicio pleno respecto a los recursos y derechos existentes. Implica, además, pensar que la política interactúe y se haga presente a través de medios de comunicación cada vez más sofisticados y multidireccionales, los cuales ya no están en las manos exclusivas de la secrecía con que la información pública era manejada desde las élites. Hoy vivimos, ciertamente, en un entorno de enorme complejidad y fluidez de datos, donde ahora el reto es cómo procesar y discernir sobre la veracidad de lo que escuchamos y vemos desde nuestros teléfonos móviles o equipos de cómputo.

Todo lo anterior no deja de ser paradójico, porque, ciertamente, nos seguimos haciendo -y lo haremos cual mito de Sísifo- la pregunta de cómo podemos tener buenos gobernantes, o cómo podríamos alentar la presencia de una ciudadanía corresponsable y no solo exigente de dádivas, la cual en los hechos sigue atrapada dentro de una condición inerme de pobreza, exclusión, manipulación e ignorancia, y en tanto se dejan de lado las cuestiones de principio, a la par que permanecen intactas las fuentes principales del problema: la permisividad frente a la corrupción, la simulación y la acepta- 
ción de los procesos de tipo clientelar/corporativo, así como la existencia de prácticas discriminatorias y violentas de todo tipo contra grupos concretos de la sociedad en razón de su género, etnia, religión u identidad. La Política (en mayúscula) fue inventada por los seres humanos y uno esperaría que a través de ella se pueden construir las respuestas y allanar los obstáculos acerca de los problemas que nos aquejan.

Mientras los procesos de la realidad mexicana empujan hacia la diversidad y pluralidad temáticas, también se puede captar que los retos que deben responder nuestros gobiernos no pueden limitarse a los temas usuales como las elecciones y los cambios de gobierno, sino que tenemos ante nosotros un inmenso territorio de exploración que se deriva de la manera misma con que los actores sociales han venido construyendo y reconfigurando la esfera misma de lo público y lo político.

$\mathrm{Al}$ realizarse este recorrido panorámico sobre las principales líneas de institucionalización y organización de la ciencia política mexicana, se pueden situar las siguientes recomendaciones, que deben permitir la generación de acciones puntuales que corresponden ejercerlas tanto al Estado (responsables de las instancias promotoras y presupuestales de la política científica y tecnológica nacional, como la Sep y el Conacyt, con sus respectivos programas y subsistemas de promoción de la investigación (Prodep y SNI); a las instancias de intermediación y representación dentro de la comunidad científica nacional (АМС, ғССут, Pro-Ciencia) y a las asociaciones gremiales especializadas en el campo de las ciencias sociales y políticas (COMECSO, AMECIP, AMEI, SOMEE, AMEP, entre las más significativas); a las instancias de acreditación de la calidad docente (CIEES, COPAES, ACCECISO y PNPC), en el sentido de conminar a las IES tanto públicas como privadas a considerar de qué manera sus programas docentes y de investigación puedan responder tanto a las necesidades de sus propias comunidades, así como insertarse en el marco de las necesidades regionales de las demandas de tipo estatal como social.

No se puede omitir la mención relativa a generar -junto con los principales indicadores descriptivos de los programas existentes- un análisis puntual en torno a los contenidos específicos de los planes y programas de estudio, a efecto de observar comparativamente los enfoques definidos en los perfiles de ingreso y egreso que las IEs están considerando para atender la evolución de los mercados laborales, a efecto de ir pasando de currículums fuertemente 
centrados en la promoción de perfiles de investigación y docencia hacia salidas y contenidos más centrados en competencias y habilidades más técnicas, así como más orientadas en los aspectos trans, ínter y multidisciplinarios, los cuales les permitan hallar ocupación en espacios como las ONG, sindicatos, partidos políticos, asesoría y consultoría dentro de instituciones públicas o empresariales.

El tema del nivel de impacto, difusión y relevancia de la investigación en los espacios de incidencia regional e internacional también debe ser considerado, pero debe hacerse más allá de las acciones asociadas con las mediciones bibliométricas, de las participaciones en congresos o seminarios; debe alentarse la búsqueda de los enfoques metodológicos de evaluación con una mayor armonización y entendimiento de los avatares del quehacer docente y de investigación.

Cabrá preguntarse entonces, de manera seria, sobre los mecanismos y rutas que puedan ser pertinentes en materia de la incidencia e intervención social y desde los cuales se pueda aportar en el marco de la implementación de acciones y decisiones directas en los campos de la política pública, todo ello de manera conjunta con los actores públicos del país. Sin duda, allí se encuentra uno de los desafíos sustantivos a ser encarados en los años por venir a los que la ciencia política mexicana debe sumarse de la misma manera que deberán hacerlo las ciencias sociales en general, para así afrontar los tiempos inciertos que estamos padeciendo. $Y$ hacerlo de manera pertinente, democrática y solidaria. Siempre habrá la exigencia de hacer más y mejor ciencia política, pero debemos estar preparados para estar a la altura de dicho reto.

\section{REFERENCIAS}

Aburto, H. (coord., 1992). Diagnóstico nacional de las licenciaturas en Ciencias Politicas y/o Administración Pública. México: Colegio Nacional de Ciencias Políticas y Administración Pública.

ACCECiso. Asociación para la Acreditación y Certificación en Ciencias Sociales (202I). <http://www.acceciso.org.mx/>. 
Acosta Silva, A. (2020). El poder de la universidad en América Latina. México: udual-Universidad de Guadalajara, Siglo xxi.

ALACip. Grupo de Investigación sobre la Historia de la Ciencia Política en América Latina (2017). Manifiesto de Popayán. Los estudios sobre historia y desarrollo de la ciencia política en América Latina: necesidades y perspectivas. Anuario Latinoamericano Ciencias Políticas y Relaciones Internacionales, vol. 5, 23I-233. doi: $<$ I0.1795I/al.20I7.5.23I >.

Alarcón Olguín, V. (20I7). La evaluación y promoción de las ciencias sociales en México. El caso de los politólogos y los administradores públicos. En F. Freidenberg (ed.). La ciencia política sobre América Latina: docencia e investigación en perspectiva comparada. Santo Domingo: Fundación Global Democracia y Desarrollo, Instituto de Investigaciones Jurídicas de la Unam, 585-633.

Alarcón Olguín, V. (20I6). Introducción. Historiar y evaluar la ciencia política en México. Un pequeño balance. En F. Barrientos del Monte (coord.). Historia y balance de la ciencia politica en México. México: coed. Tirant Lo Blanch, Universidad de Guanajuato, I6-3I.

Alarcón Olguín, V. (2012). La ciencia política mexicana. Reflexiones sobre su pasado, presente y porvenir. Politica. Revista de Ciencia Política, vol. 50, núm. I, 3I-57. Santiago: Universidad de Chile-Instituto de Asuntos Públicos, <https://revistapolitica.uchile. $\mathrm{cl} /$ index.php/RP/article/download/22648/23968/>.

Alarcón Olguín, V. (20II). La ciencia política en México. Trayectorias y retos de su enseñanza, México: Editorial Torres Asociados.

Alcántara Saéz, M. (1993). Cuando hablamos de ciencia política, ¿de qué hablamos? Revista Mexicana de Sociología. vol. 55, núm. 4, I47-I78. <https:/gredos.usal.es/bitstream/handle/IO366/I8498/ DDPG_Cuandohablamos.pdf? sequence $=\mathrm{I} \&$ isAllowed $=\mathrm{y}>$.

Aldeguer Cerdá, B. (2015). ¿Qué son la ciencia política y la ciencia de la administración? En G. Sánchez Medero y R. Sánchez Medero (eds.). Fundamentos de la Ciencia Politica y de la Administración. Madrid: Tecnos, I7-54. 
Almond, G. (1990), A Discipline Divided. Schools and Sects in Political Science. Beverly Hills, CA: Sage Publishers (Traducción al castellano: Una disciplina segmentada. Escuelas y corrientes en las ciencias politicas. México: FCE-CNCPYAP, 1999).

Altman, D. (20I7). Enseñando y entrenando. ¿Dónde se genera conocimiento? Sobre la productividad e impacto de los departamentos de Ciencia Política en América Latina. En F. Freidenberg (ed.). La ciencia politica sobre América Latina: docencia e investigación en perspectiva comparada. Santo Domingo: Fundación Global Democracia y Desarrollo, Instituto de Investigaciones Jurídicas-Unam, 559-583.

Ángel Baquero, S. (2020). Debates acerca de la enseñanza y la profesión dentro de los estudios sobre historia y desarrollo de la ciencia política: un panorama de las últimas dos décadas. En F. Sánchez y N. Liendo (eds.). Manual de ciencia politica y relaciones internacionales. Bogotá: Universidad Sergio Arboleda, 19-46.

Anuies. Asociación Nacional de Universidades e Instituciones de Educación Superior. (202I). Catálogo de Instituciones, <http://www. anuies.mx/anuies/instituciones-de-educacion-superior/>.

Anuies (202I). Mapa de Consejos Regionales. <http://www.anuiescrne. uadec.mx/wp-content/uploads/2019/o4/INICIO.png>.

Arellano Ríos, A. (20I5). La ciencia política en el estado de Jalisco: un balance de su institucionalización. Estudios Políticos (Unam), vol. 9, núm. 34, I39-165. <http://www.scielo.org.mx/pdf/ep/n34/ n34a7.pdf >.

Barrientos del Monte, F. (2015). Crecimiento e institucionalización de la ciencia política en México. Revista de Ciencia Política, vol. 35, núm. I, 95-I20. <https://www.redalyc.org/pdf/324/32439319006. pdf $>$.

Barrientos del Monte, F. (20I4). Buscando una identidad. Breve historia de la ciencia política en América Latina. México: Fontamara.

Béjar Navarro, R. y Hernández Bringas, H. (1996). La investigación en ciencias sociales y humanidades en México. México: UNAM-CRIM, Miguel Ángel Porrúa. 
Bensusán, G y Valenti, G. (coords., 20I8). La evaluación de los académicos. Instituciones y Sistema Nacional de Investigadores, aciertos y controversias. México: FLACSO, UAM-Xochimilco.

Blondel, J. (1978). Thinking Politically. Londres: Penguin Books.

Bokser, Liwerant, Judit (1999). El estado actual de la Ciencia Política. En M. Merino (coord.). La ciencia política en México. México: Conaculta, FCE, 23-55.

Bourdieu, P. (2003). El oficio del cientifico. Ciencia de la ciencia y reflexividad. Barcelona: Anagrama.

Bravo-Ahuja, M. (20i6). La encrucijada de la ciencia política en el siglo Xxi. En R. Uvalle, J. C. Luna y M. Singer (coords.). Construcción y tendencias de la ciencia política y la administración pública en el siglo XXI. México: Unam, Fes-Acatlán, FCPys, 289-302.

Bulcourf, P., Gutiérrez Márquez, E. y Cardozo, N. (2015). Historia y desarrollo de la ciencia política en América Latina: Reflexiones sobre la constitución del campo de estudios. Revista de Ciencia Política. 35(I), I79-I99. <https://www.redalyc.org/pdf/324/32439319009. $\mathrm{pdf}>$.

Bunge, M. (1998). Sociología de la ciencia. Buenos Aires: Sudamericana. CIEEs. Comités Interinstitucionales de Evaluación de la Educación Superior (202I). Padrón general de acreditación de programas e instituciones. <https://www.ciees.edu.mx/instituciones_acreditadas/>.

Codato, A., Madeira, R. y Bittencourt, M. (2020). Political Science in Latin America: a Scientometric Analysis. Brazilian Political Science Review. A Journal of the Brazilian Political Science Association, I4(3), I-35. <https://brazilianpoliticalsciencereview.org/wp-content/uploads/articles_xml/I98I-382I-bpsr-I4-3-eooo7/I98I-382Ibpsr-I4-3-e0007.x89995.pdf>.

comecso, Consejo Mexicano de Ciencias Sociales (202I). <https://www. comecso.com/que-es-comecso>.

comicip. Consejo Mexicano de Investigación en Ciencia Política (2013). La ciencia política en México. Cifras. México: comicip. (Cuaderno de Trabajo, n.I). <http://www.comicip.org.mx/docdetrabajor.comicip.pdf>. 
Contreras Montellano, O.F. y Puga, C. (coords., 2019). Las ciencias sociales y el Estado nacional en México. México: FCE.

Contreras Montellano, O.F. y Puga, C. (20I7). La expansión desigual de las ciencias sociales en México. En C. Puga (coord.). Un panorama de las ciencias sociales en México. México: Unam, FCPys, La Biblioteca, I7-42.

Conacyt (202I). Archivo histórico / SNI -Padrón de Beneficiarios 2020. $<$ https://www.conacyt.gob.mx/Archivo-Historico.html>.

Conacyt (202I). Bases de datos abiertos/Sistema Nacional de Investigadores

- S I9I. <https://www.siicyt.gob.mx/index.php/sigI-sistema-nacional-de-investigadores-sni/2-uncategorised/22o-bases-de-datos-abiertas-sI9I>.

Conacyt (202I). Sistema de Clasificación de Revistas Mexicanas de Ciencia y Tecnología. <http://www.revistascytconacyt.mx/>.

Conacyt (202I). Padrón Nacional de Posgrados de Calidad - Programas acreditados. <http://svrtmp.main.conacyt.mx/Consultasp NPC/ padron-pnpc.php>.

COPAes (202I). Consejo para la Acreditación de la Educación Superior. Padrón de Programas Acreditados a Nivel Nacional. <https:// www.copaes.org/consulta.php>.

Cuéllar Argote, J.C. y Caicedo Ortiz, J.C. (2015). ¿Hacia dónde va la ciencia politica? Reflexiones sobre la disciplina en Colombia. Ibague: Universidad del Tolima.

Della Porta, D. y Keating, M. (2013). ¿Cuántos enfoques hay en ciencias sociales? Introducción epistemológica. En D. della Porta y M. Keating (eds.). Enfoques y metodología de las ciencias sociales. Barcelona: Akal, 3I-5I.

Duque Daza, J. (2020). Politología. La ciencia politica y la formación del politólogo. Medellín: La Carreta.

Duque Daza, J. (20I4). La ciencia politica en Colombia. La construcción de una comunidad cientifica. Cali: Ediciones de la Universidad del Valle.

Echeverría, J. (2009). Los sujetos de las ciencias. En F. Broncano y A. Pérez Ransanz (coords.). La ciencia y sus sujetos. ¿Quiénes hacen la ciencia en el siglo XXI? México: Coed. Unam, Siglo XXI, I9-26. 
Easton, D. (1985). Political Science in the United States. Past and Present. International Political Science Review, 6(I), I33I52. <http://www.revistas.unam.mx/index.php/rep/article/ view/5974I/52683>.

Elliott, P. (I975). Sociología de las profesiones. Madrid: Tecnos.

FIMPES, Federación de Instituciones Mexicanas Particulares de Educación Superior (202I). Catálogo de instituciones. <https://www.fimpes.org.mx/index.php/instituciones/instituciones>.

Flores Mariscal, J.R.J. (20I6). Evolución de la literatura sobre el estado de la ciencia política en México (1947-2015). Otra mirada del proceso de desarrollo de la disciplina. Revista Mexicana de Ciencias Politicas y Sociales 6I(227), 55-IO2. <http://www.revistas.unam. $\mathrm{mx} /$ index.php/rmcpys/article/view/50526/49066>.

Freidenberg, F. y Suárez Cao, J. (202I). Creando redes de mujeres en una disciplina masculinizada: el caso de la Red de Politólogas. Polis. Revista Latinoamericana. (Chile). 20(59), I47-I64. doi: <I0.32735/ So718-6568/202I-N59-I592>

Garcé, A. (2020). ¿Clima de perestroika? La ciencia política latinoamericana en tiempos de debate. En E. Gutiérrez Márquez y R. Torres Ruiz (coords.). Reflexiones en torno a la ciencia politica y la política en América Latina. México: Universidad Iberoamericana, 29-44.

García Díaz, V. (2016). Caminos hacia la academia. Relatos de vida, identidad y profesión. Zinacantepec: El Colegio Mexiquense.

Graziano, L. (1987). Para una historia de la ciencia política. Papers. Revista de Sociología, 28, 27-56. doi: <http://dx.doi.org/I0.5565/rev/ papers/v28no.i524>.

González Casanova, P. (1968). Aritmética contrarrevolucionaria. En J. Sánchez Azcona (comp.). (1980). Lecturas de Sociología y Ciencia Política. México: Unam-Coordinación de Humanidades, 6I-69.

Herrera. A.O. (1975). Ciencia y politica en América Latina. México: Siglo XXI.

Holmes, R. (20I2). La edad de los prodigios. Terror y belleza en la ciencia del Romanticismo. Colección Noema. Madrid: Turner.

Hoyo Arana, J.L. (1980). En torno al objeto y método de la ciencia política, En J. Montaño (coord.). Las humanidades en el siglo 
XX. T. 3: Las ciencias sociales. México: Unam-Coordinación de Humanidades, 45-58.

Kent, R., Álvarez Mendiola, G., González Rubí, M., Ramírez García, R y De Vries, W. (2003). Cambio organizacional y disciplinario en las ciencias sociales en México. México: Cinvestav, Plaza y Valdés.

King, G., Lehman, Ky Nie, N. (2009). An Introduction to The Future of Political Science. En G. King, K. Lehman y N. Nie (eds.). The Future of Political Science. Ioo Perspectives. Nueva York: Routledge, I3-20.

Lave. J. (200I). La práctica del aprendizaje. En S. Chaiklin y J. Lave (comps.). Estudiar las prácticas. Perspectivas sobre actividad y contexto. Buenos Aires: Amorrortu, I5-45.

Loaeza, S. (2005). La ciencia política: el pulso del cambio mexicano. Revista de Ciencia Politica, 25(I), 192-203. <https://www.redalyc. org/pdf/324/32425II5.pdf>.

Meyer, L. y Camacho, M. (1979), La ciencia política en México. En varios autores. Sociología y ciencia politica en México (un balance de veinticinco años). México: Unam, FCPys, 63-IO2.

Meyer, L. (197I). La ciencia política y sus perspectivas en México. Historia Mexicana, vol. 2I, núm. 2, 285-3II. <https://historiamexicana. colmex.mx/index.php/RHM/article/view/2543/2055>.

Miller, A.H. (1977). The Ethics of Teaching Political Science. Another perspective. En S. Hook, P. Kurtz y M. Todorovich (eds.). The Ethics of Teaching and Scientific Research. Buffalo, N. Y.: Prometheus Books, 43-48.

Monroe, K.R. (ed., 2005). Perestroika! The Raucous Rebellion in Political Science. New Haven: Yale University Press.

Muñoz Patraca, V.M. (2009). La disciplina de la ciencia política. Estudios Políticos (Unam), vol. 9, núm. I7, 9I-I08. <https://www.redalyc. org/pdf/4264/4264399760o6.pdf>.

Murillo, M.V. (2015). La contextualización en ciencia política: una perspectiva latinoamericana. Foro Internacional, vol. LV, núm. 220, 576-594. <https://www.redalyc.org/pdf/599/59944853007.pdf>. 
Munck, G. (2007). Agendas y estrategias de investigación en el estudio de la política latinoamericana. Revista de Ciencia Política, vol. 27, núm. I, 3-2I. <https:/www.redalyc.org/pdf/324/32427IoI.pdf>.

Nohlen, D. (20II). Cómo estudiar ciencia política. Lima: Ediciones Pontificia Universidad Católica del Perú.

Panebianco, A. (20II). Las ciencias sociales y la política. En J. Sánchez y J. Russo (eds.). Repensar la ciencia política. México: Miguel Ángel Porrúa, 9-95.

Pasquino, G. (20I0). La ciencia política en un mundo en transformación. Studia Politica, 2I, 23-37. <https://fundamentoscpuba.files.wordpress.com/2015/Io/7dif5-pasquino-gianfranco-20Io-e2809cla-ciencia-polczadtica-en-un-mundo-en-transformacic3b3ne28o9d.pdf>.

Perestroika, Mr. (2000). On the Irrelevance of APSA and APSR to the study of Political Science. <https://ia80o208.us.archive.org/o/items/ OnTheIrrelevanceOfApsaAndApsrToTheStudyOfPoliticalScience/mrperestroika.pdf>.

Pérez Mora, R., Prieto Quezada, M.T. y Castellanos Gutiérrez, J.C. (20I2). Las condiciones de producción intelectual de los académicos. Prolegómenos epistémico-metodológicos hacia la construcción de un objeto de estudio. En J. Naidorf y R. Pérez Mora (coords.). Las condiciones de producción intelectual de los académicos en Argentina, Brasily México. Buenos Aires: Miño y Dávila, I3-32.

Puelló-Socarrás, J.F. y Jiménez, C. (2019). Entre la ciencia política convencional y la(s) politología(s) alternativa(s): hitos históricos y debates actuales. Ciencia Politica (Universidad Nacional de Colombia), vol. I4, núm. 27, I75-205. doi: <https://doi.org/IO.I5446/ cp.vi4n27.74967>.

Puente Martínez, K. y Martínez Valdés, G. (2017). Estilos de producción científica en la investigación en ciencia política en la Unam (20IO-20I4). En K. Puente Martínez y F. Mancini (eds.). Las ciencias sociales en la Unam. Análisis de la producción académica contemporánea. México: Unam-FCPys, 6I-88.

Ravecca, P. (2019). The Politics of Political Science. Re-writing Latin American Experiencies. Londres: Routledge. 
Red de Politólogas/No Sin Mujeres (2019). Manifiesto de la Red de Politólogas. <https://www.nosinmujeres.com/publired/manifiestored/>.

Remedi Allione, E. y Ramírez García, R.G. (20I6). Sujetos, grupos, instituciones y disciplinas en la construcción de trayectorias y campos científicos. Notas introductorias. En E. Remedi Allione y R.G. Ramírez García (coords.). Los cientificos y su quehacer. Perspectivas en los estudios sobre trayectorias, producciones y prácticas cientificas. México: Anuies, 13-35.

Retamozo, M. (2009). La ciencia política contemporánea: ¿constricción de la ciencia y aniquilamiento de lo político? Apuntes críticos para los estudios políticos en América Latina. Andamios, vol. 6, núm. II, 7I-IOO. <http://www.scielo.org.mx/scielo.php?scrip$\mathrm{t}=$ sci_arttext\&pid=SI870-00632009000200004\&lng=es\&tln$\mathrm{g}=\mathrm{es}>$.

Ricci, D.M. (1984). The Tragedy of Political Science. Politics, Scholarship and Democracy. New Haven: Yale University Press.

Rivera, M. y Salazar Elena, R. (20II): El estado de la ciencia política en México. Un retrato empírico, Política y Gobierno, vol. ı8, núm. I, 73-I08. <http://politicaygobierno.cide.edu/index.php/pyg/ article/view/I68/85>.

Rodríguez Araujo, O. (200I). La ciencia política en (y sobre) México en el siglo xx. Revista Ciencia (Academia Mexicana de Ciencias), vol. 52, núm. 4, 66-75. <http://revistaciencia.amc.edu.mx/images/ revista/5I_3/ciencia.politica.pdf>.

Rodríguez Sala-Gómez Gil, M.L. y Chavero González, A. (1982). El cientifico en México: su formación en el extranjero, su incorporación y adecuación al sistema ocupacional mexicano. México; CESU, Unam.

Roqueñí Ibargüengoitia, M.C. (20I4). Feminización de la Licenciatura en Ciencia Política en México. ¿Igualdad de oportunidades o inclusión desigual? En Estudios Políticos. (Unam), núm. 32, I53I73. <https://core.ac.uk/download/pdf/82764885.pdf>.

Salas-Porras Soulé, A. (20I8). Conocimiento y poder. Las ideas, los expertos $y$ los centros de pensamiento. Colección Foca. Madrid: Akal. 
Salomon, J.J. (1974). Ciencia y política. México: Siglo XXI.

Sandel, M.J. (2020). La tiranía del mérito. ¿Qué ha sido del bien común? Barcelona: Debate.

Sartori, G. (20II). Cómo hacer ciencia politica. México: Taurus.

Sartori, G. (2004). Hacia dónde va la ciencia política. Política y Gobierno, vol. XI, núm. 2, 349-354. <http://www.politicaygobierno.cide. edu/index.php/pyg/article/view/330/240>.

Schmitter, P.C. y Blecher, M. (202I). Politics as a Science. A Prolegomenon. Nueva York: Routledge.

Schmitter, P.C. (2003). Siete tesis (disputables) acerca del futuro de la Ciencia Política 'transatlantizada' o 'globalizada', POSTData, núm. 9, 2003, 59-8o. <https://drive.google.com/file/d/oB637k_ n5waBpzGewnTY5YjQtNmNknsoontgolwiyogytmT FhodMxownhogrz/view>.

Shaw, M. (1978), El marxismo y las ciencias sociales. México: Nueva Imagen.

Tanaka, M. y Dargent, E. (2015). ¿Qué implica hacer ciencia politica desde el sur y desde el norte? Lima: Pontificia Universidad Católica del Perú. <https://escuela.pucp.edu.pe/gobierno/wp-content/uploads/2016/03/14820-\%c2\%bfQu\%c3\%a9-implica-hacer-Ciencia-Politica-desde-el-Sur...-WE B-I.pdf>.

Torres Mejía, D. (1990). La ciencia política en México. En F. Paoli Bolio (coord.). Desarrollo y organización de las ciencias sociales en México, México: $\mathrm{CIICH}-$ Unam.

Vallés, J. (2020). ¿Para qué servimos los politólogos? Madrid: Los Libros de la Catarata.

Vidal de la Rosa, G. (2013). Ensayos sobre la ciencia politica en México y Latinoamérica. México: UAM-Azcapotzalco.

Yocelevzky Retamal, R. (20I4). Contribuciones para una historia de las ciencias sociales en América Latina. México: UAM-Xochimilco.

Zamitiz Gamboa, H. (2020). ¿Qué es la ciencia politica? Serie Working Papers. México: Unam-FCPys.

Zolo, D. (2007). La «tragedia» de la ciencia política. Temas y Debates. Revista Universitaria de Ciencias Sociales, I4, 5I-69. <http://rephip. unr.edu.ar/bitstream/handle/2133/I463/La_tragedia_de_la_ciencia_politicaTyDi4.pdf?sequence $=\mathrm{I}>$. 